\title{
Towards Sustainable Land Uses within the Elbe River Biosphere Reserve in Lower Saxony, Germany by Means of TerraSAR-X Images
}

\author{
Dalia Farghaly, Emad Elba, Brigitte Urban \\ Faculty of Sustainability Sciences, Institute of Ecology, Subject Area Landscape Change, LEUPHANA University \\ of Lüneburg, Lüneburg, Germany \\ Email: dalia.farghaly@stud.leuphana.de
}

Received 29 January 2016; accepted 28 March 2016; published 31 March 2016

Copyright (C) 2016 by authors and Scientific Research Publishing Inc.

This work is licensed under the Creative Commons Attribution International License (CC BY).

http://creativecommons.org/licenses/by/4.0/

(c) (i) Open Access

\begin{abstract}
Floods are one of the major hazards worldwide. They are the source of huge risks in rural and urban areas, resulting in severe impacts on the civil society, industry and the economy. The Elbe River has suffered from many severe floods during recent decades. In this study, the zones flooded during 2011 were analyzed using TerraSAR-X images and a digital elevation model for the area in order to identify possible ways to mitigate flood hazards in the future, regarding sustainable landuse. Two study areas are investigated, around the Walmsburg oxbow and the Wehningen oxbow. These are located between Elbe-Kilometer (505-520) and (533-543), respectively, within the Lower Saxonian Elbe River Biosphere Reserve. Those areas are characterized by several types of land use, with agricultural land use being predominant. The study investigated the possibility of using a Decision-Tree object-based classifier for determining the major land uses and the extent of the inundation areas. The inundation areas identify for 2011 submerged some agricultural fields that must be added to existing flood risk maps, and future cultivation activities there prevented to avoid the possible economic losses. Furthermore, part of the residential area is located within the high flood zone, and must be included in risk maps to avoid the possible human and economic losses, to achieve sustainable land use for the areas studied.
\end{abstract}

\section{Keywords}

Elbe River, Floods, Land Use, SAR, TerraSAR-X, Decision-Tree, Object-Based Classification, Risk Maps 


\section{Introduction}

The Elbe River is the fourth largest river basin in Europe, after the Danube, the Vistula, and the Rhine [1]. The Elbe runs through Austria, the Czech Republic, Poland, and Germany. The river is about $1094 \mathrm{~km}$ long, with about $727 \mathrm{~km}$, or $66 \%$ of its length, being in Germany. The river basin area covers about $148,000 \mathrm{~km}^{2}$. $65 \%$ of the catchment lies in Germany, with an area of about 97,000 km² [2]-[4]. The Elbe has several gauges to measure water levels along the river, as shown in Figure 1 [5]. The Czech-German state border marks the zero point for the Elbe kilometrage, with the numbers increasing in the upstream direction on the Czech side, and increasing in the downstream direction on the German side [1] [6].

The Elbe floodplain was designated as a Biosphere Reserve (Flusslandschaft Elbe) by UNESCO in 1997. It consists of four reserves, namely the Biosphärenreservat Mittelelbe in Sachsen-Anhalt, the Biosphärenreservat Flusslandschaft Elbe-Brandenburg, the Biosphärenreservat Flusslandschaft Elbe-Mecklenburg-Vorpommern, and the Biosphärenreservat Niedersächsische Elbtalaue [7] [8]. The Elbe River Biosphere Reserve in Lower Saxony reaches from Schnackenburg in the southeast, at Elbe-km 472.5, to Hohnstorf in the northwest, at Elbe-km 569, and has an area of about $568 \mathrm{~km}^{2}$. The elevation of the terrain ranges from $5 \mathrm{~m}$ to $109 \mathrm{~m}$ above mean sea level. The floodplains are used in various ways, with a predominance of agricultural land use. Equal portions of $34 \%$ are covered by agricultural fields and grassland areas, while a portion of $22 \%$ is covered by forest. The rest is divided equally between water bodies and residential areas [9]-[11]. The Elbe floodplain suffered from large-scale century flooding in 2002, which caused huge damage in hazardous areas of the Elbe catchment. Consequently, many studies have been conducted to improve flood-risk management plans for the Elbe basin [12] [13].

In Germany, 21 people were killed, 100 people were injured, and 200,000 people were evacuated from the $300 \mathrm{~km}^{2}$ inundation extent area along $800 \mathrm{~km}$ of the river, resulting in economic losses of 11.6 billion, caused by the large-scale century flooding in 2002 [14]-[17]. Since 2002, Germany has conducted several measures to improve flood-risk management and reduce the flood hazards [18] [19]. Therefore, although the two extreme century floods in 2011 and 2013 were actually higher than that in 2002, they did not cause as much damage as the one in 2002 [14]. In recent years, flood protection structures throughout Germany have been extensively upgraded. Flooding occurred in 2011 and resulted in damage in the catchments of the Rhine, the Danube, the Weser,

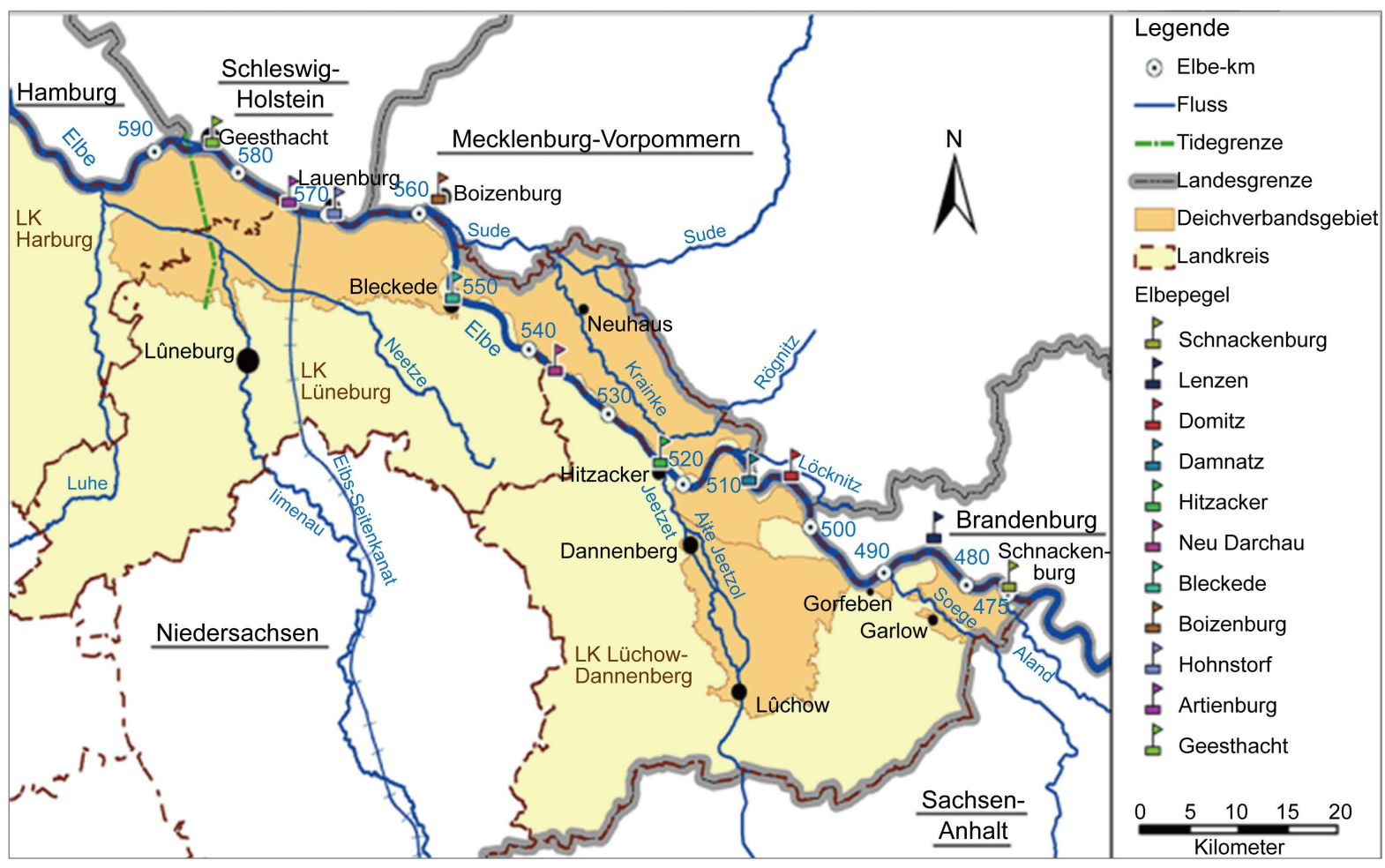

Figure 1. Gauge locations along the Elbe [5]. 
and the Elbe. However, in spite of the extent of the flooding, disastrous damage did not occur. The total damage was estimated to be more than 100 million Euro in Germany, an amount that was much smaller than the 11.6 milliard Euro in 2002, for example [12] [20]. Likewise, in some areas, damage was minimal or almost completely avoided during the floods in 2013. Nevertheless, the 2013 floods also caused severe problems in other areas: eight people were killed, and 52,000 were evacuated across parts of the $200 \mathrm{~km}^{2}$ drowned area, leading to a loss of approximately 12 milliard Euro [21]-[23].

Comparing of the areas affected in 2013 with existing flood hazard and risk maps, one can see that these flood maps are usually reliable [24]. However, some investigations in flooded areas showed that some people affected by the flood of 2013 had already forgotten about the damage that occurred in the 2002 floods and, faced with the recurrent flooding in 2013, were unable to deal with the disaster since many believed they could only have infrequent exposure to century floods [14]. Awareness of flood risks played a major role in how serious the damage caused by the 2013 flood was in any given area. Thus, it is essential that people are aware of flooding as an intrinsic part of their environment, an awareness that can be achieved through flood hazard and risk maps that give them an idea about flood prevention and protection plans [24] [25]. These maps should be made more widely accessible and used more actively. To ensure efficient use of flood maps and risk awareness programs, they must be integrated into the planning processes for risk mitigation policies and new construction projects. There was no real legislative limitation on building new construction in areas designated as hazardous by flood maps. After the 2002 flood, legislative limitations were declared limiting new settlements in flood-prone areas; however, they were undermined to a very considerable scale by several exceptions. The extreme flood of 2013 and the consequent damages demonstrate that new flood risk management plans are required [14].

Flood risk is the combination of the probability of a flood event and of the possible deleterious consequences to human health, the environment and economic activity associated with the flood event. Flood risk management includes the comprehensive and continuous assessment and evaluation of flood hazard and flood risks, to mitigate the floods and/or the impact of floods. The flood risk management programs integrate five measures namely, prevention, protection, awareness, emergency response, and recovery. Prevention measures seek to prevent damage caused by floods by avoiding construction of houses and industries in present and future flood-prone areas, by adapting future developments to the risk of flooding, by promoting proper land-use, and by adapting to changing risk factors such as climate change. Protection measures seek to take both structural and non-structural measures to mitigate the impact of floods in a specific location by construction of flood dikes, and early warning systems. Awareness measures seek to inform the population about flood risks, settlement expansion in safe places using suitable forms of construction, and what to do in the event of a flood. Emergency response measures seek to develop emergency response plans in the case of a flood. Recovery measures seek to return to normal conditions as soon as possible and mitigate both the social and economic impacts on the affected population [26]-[29]. For effective and efficient flood risk management, comprehensive information about the existing hazards and risks throughout the river basin, including flood type, the probability of a particular flood event (low, medium, high), the flood extent, water depth, flow velocity and possible damages, is required [26] [30] [31]. Therefore, flood maps are useful tools that provide information about hazards, vulnerabilities, and risks of a given area.

Flood maps include flood hazard maps, which identify the extent of flooded areas at different flood probabilities. They also include flood risk maps, which indicate the possible harmful consequences associated with floods of different probabilities, especially when correlated with land use maps. Furthermore, detection maps can show the inundation extents of former floods [30]-[32]. These flood maps should be included into spatial and emergency planning beside the information from Geographic Information Systems (GIS) to achieve reduction and mitigation of possible damage [28] [33]. Historical flood detection maps, land use maps, and other sources of historical information about former flood areas are essential in identifying flood hazards and to create risk maps that can serve as a basis for crucial flood protection, land zoning, and development restrictions in flood hazard areas. In short, there is a need for up-to-date flood detection and land use maps [28] [34]-[37]. Furthermore, flood-detection mapping is required in many applications such as disaster management, risk damage assessment, and rehabilitation processes. Flood-mapping monitoring techniques use pre- and post-satellite imagery [38]-[40]. Floods often happen in combination with heavy rains and dense cloud cover which affect optical satellite images. Synthetic Aperture Radar (SAR) imagery is not affected by these weather conditions because it does not rely on sunlight, and thus can also be used at night. Hence, SAR imagery is especially practical in flood detection mapping. Therefore, there are many studies about using this type of imagery as a flood detection tool [41] [42]. 
Generally, flood mapping is obtained using image classification, where each individual pixel is classified based on all existing information using the grey values and spatial information of an image [26] [30]-[32]. The satellite imagery can be classified on a pixel-based or object-based basis. Pixel-based image processing classifies single pixels according to their spectral reflectance. Object-based image processing has two steps: segmentation and classification. Segmentation is the process of dividing an image into a network of homogeneous image objects by grouping together neighboring pixels with similar feature values such as brightness, texture, color, etc. The segments ideally correspond to real-world objects and contain additional information relevant to classification, such as shape, texture and relationships to neighboring objects. Image texture provides information about the spatial arrangement of color or intensities in an image or selected region of an image. The classification of image objects (contextual classification) is carried out after segmentation. The contextual classification is based not only on spectral statistics, but also on the additional information including shape, texture and network relationship, and this enables the segmented image objects to be related to land cover classes. Contextual classification offers some advantages over traditional classification, because segmentation reduces the total number of elements that need to be handled during classification, thus significantly reducing the work needed to perform classification. Moreover, classification segmenting with homogeneous regions reduces salt-and-pepper noise in the classification results [35] [43]-[45].

Several studies have investigated the effect of the surface roughness on the radar backscattering. Surface roughness is the main factor affecting radar backscattering and determines the angular distribution of surface scattering, as shown in Figure 2 [46]. The greater the roughness of a surface, the more the incident radiation will be backscattered to the radar; thus, the rougher a surface, the lighter it will appear in radar imagery. Smooth surface boundaries, such as water areas, act as mirrors and scatter the energy away from the sensor. In this case, the angle of reflection, $\theta_{e}$, is equal to the angle of incidence, leading to a very low signal return, in turn producing relatively dark pixels in radar data. With an increasing roughness, the fraction of backscatter to the sensor grows larger. Very rough surfaces scattered the energy equally in all directions, including back to the sensor, and thus return a significant part of the transmitted energy back to the sensor [43] [45] [47].

Several studies have also investigated the effect of the wavelength of SAR sensors on mapping water and the vegetation canopy. The longer the system's wavelength, the greater the ability of the signal to penetrate the vegetation canopy, as shown in Figure 3 [43] [46]. L-band SAR sensors, with wavelengths of 19 to $77 \mathrm{~cm}$, are effective for mapping flooding in forest environments. By contrast, C-band sensors, with wavelengths of 4.8 to 7.7 $\mathrm{cm}$, and X-band sensors, with wavelengths of 2.8 to $5.2 \mathrm{~cm}$, cannot penetrate the vegetation canopy, because

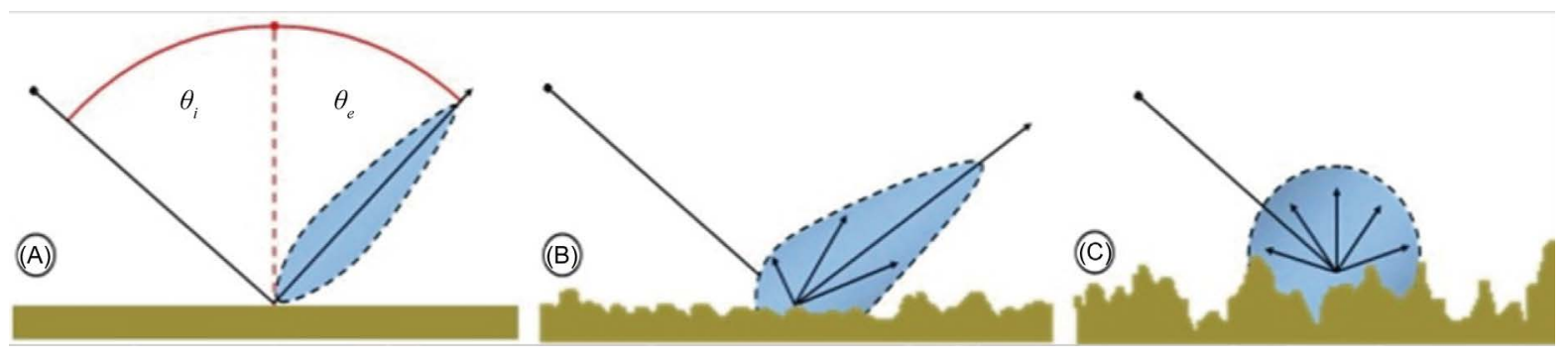

Figure 2. Radar reflection of (A) smooth, (B) moderately roughened and (C) strongly roughened surfaces [43] [46].

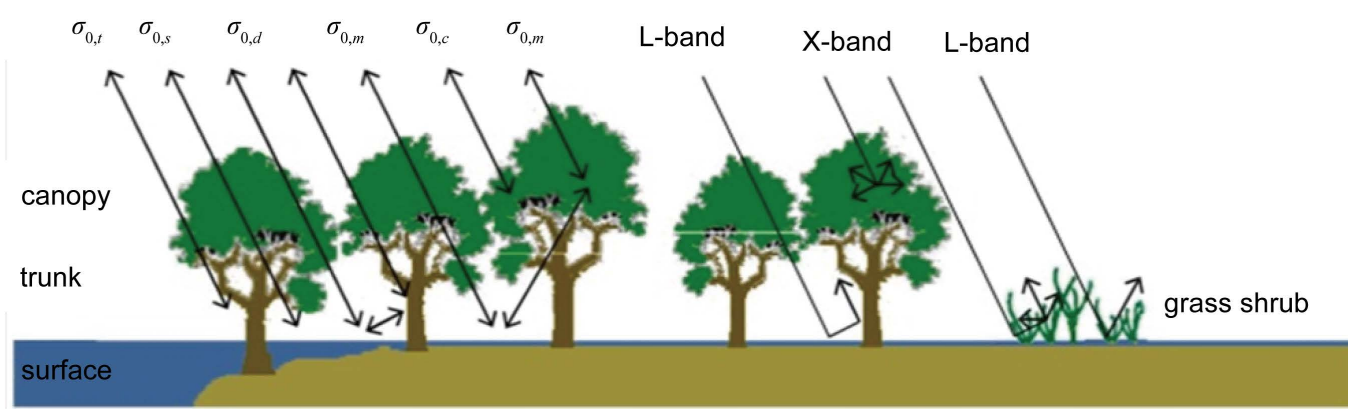

Figure 3. Conceptual illustration of the major sources of backscatter from vegetation and effect of flooded vegetation on Xand L-band SAR [43] [46]. 
these wavelengths produce more surface scattering from the top layer of the forest canopy. Therefore, neither C-band nor X-band SAR sensors are effective for mapping flooding in forest environments [45] [48] [49].

The effectiveness of different SAR and optical images in water delineation and flood detection applications has been evaluated in the literature using several classification methods. Numerous studies used optical images in identifying the extent of water areas. Reference [50] used Landsat TM imagery in extracting contour lines that mapped the bed of the High Aswan Dam Reservoir and allowed the lake's current morphology to be determined. Reference [42] created the Modified Normalized Difference Water Index (MNDWI) using Shuttle Radar Topographic Mission (SRTM) DEM and ASTER and LANDSAT satellite images to identify moist surfaces or saturated areas to separate flooded and non-flooded areas and to generate a flood hazard map. Reference [51] used Landsat TM imagery to map Lake Kyoga from 1972 till 2004, and Aster imagery in 2008 and 2009, to study the history of problematic aquatic plants in the lake. Supervised classification was performed for each image to identify the lake boundary.

Numerous studies have investigated the effectiveness of SAR imagery in identifying flooded areas. Several investigations applied Thresholding — methods to SAR imagery in order to locate flooded areas. Reference [32] used Threshold-based image segmentation and texture analysis methods in processing Multi-temporal NOAA AVHAR and RADARSAT images to achieve real-time and all-weather monitoring of floods. Reference [44] studied the possibility of optimizing the threshold ranges for the classification of flood water in SAR images for quick flood inundation mapping and response during flood disasters. For different polarizations, the mean backscattering signature profiles of various water bodies were analyzed to discriminate flood water from other water bodies. The study showed that using HH polarization imagery enables better delineation of the land-water surface.

Reference [52] developed an algorithm to map flooded areas from COSMO-SkyMed X-band SAR imagery based on fuzzy logic that can integrate theoretical knowledge about the radar return from inundated areas, described by means of three electromagnetic scattering models, with simple hydraulic considerations and contextual information using also auxiliary data, such as a land cover map and a digital elevation model. Reference [35] tested three different speckle noise removal filters including Lee, Frost, and Gamma MAP filters. The Gamma MAP filtered image had the best results and was segmented using Gray Level Co-occurrence Matrix (GLCM) and Mean Shift Segmentation (MSS). It was found that MSS is efficient for flood mapping.

Although many procedures have been studied in the literature, the present research focuses on Decision-Tree methodology, which has not been comprehensively evaluated. The present research employs remote sensing tools in identifying the detection maps and land use/land cover LULC maps using TerraSAR-X (TSX) imagery for two study areas within the Elbe Biosphere reserve in Lower Saxony "Niedersächsische Elbtalaue". Both the LULC and flood-detection maps are generated using a Decision-Tree object-based classifier. These maps can be used in updating the flood hazards and risk maps of this area, and to enable sustainable use of the land resources in the study area.

\section{Methods and Materials}

\subsection{Study Area}

Two pilot areas are selected, around the Wehningen Oxbow, lying between Elbe-Kilometers (505-520), and the Walmsburg Oxbow, between Elbe-Kilometers (533-543), within the Lower Saxonian Elbe River Biosphere Reserve (Figure 4). $30 \%$ of this area is covered by forests, which must be maintained to ensure the sustainability of the flood plain environment. Over $65 \%$ of this area is covered by agricultural fields and grasslands.

\subsection{Data Collection}

The water levels measured by Wasser- und Schifffahrtsverwaltung des Bundes (WSV), and provided by Bundesanstalt für Gewässerkunde (BfG), at the Neu Darchau gauge (Walmsburg Oxbow) and at the Damnatz gauge (Wehningen Oxbow) were collected for the periods from January 2010 until December 2012 and during June 2013. The readings of both gauges were converted to real water levels above mean sea level. The TerraSAR-X images (TSX) used were acquired during the period from March 2010 to January 2012 provided by the German Aerospace Centre (DLR). These images are acquired by the German Earth observation satellite. Its orbit passes over the same location every 11 days. It uses an X-band SAR, with $31 \mathrm{~mm}$ wavelength and $9.6 \mathrm{GHz}$, frequency 


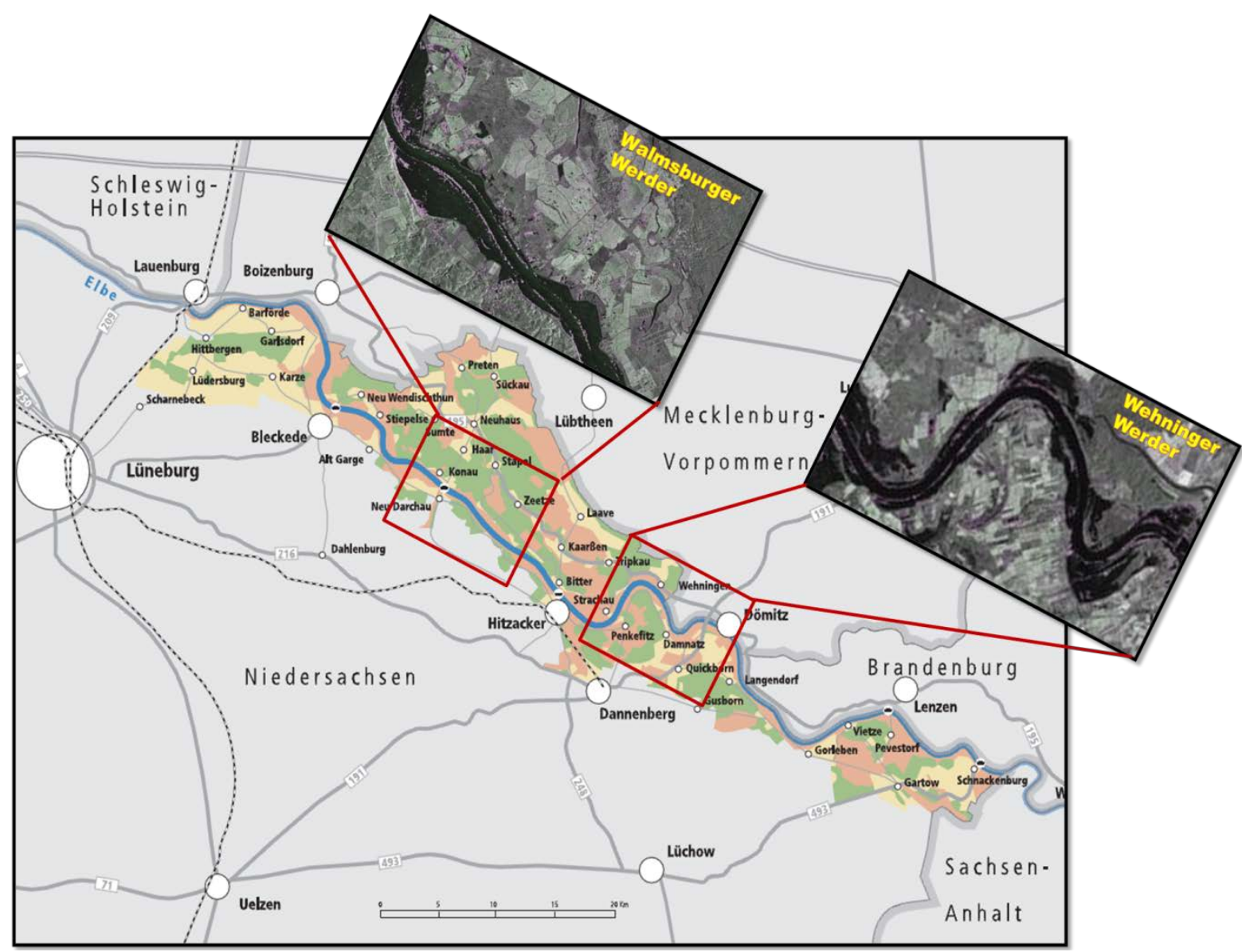

Figure 4. Location of study areas within the Lower Saxonian Elbe River Biosphere Reserve.

providing high-quality topographic information [53]. Orders were submitted to obtain images covering the flood peaks but, due to some technical problems, images of the peak water levels were not available. The TSX images were Dual Polarization Spotlight products, generated by the DLR as Multi-look Ground-range Detected (MGD) products with Spatially Enhanced (SE) processing. MGD has reduced speckle and approximately square resolution cells on the ground. The dual polarization TSX imagery collects data at HH for horizontal transmit and horizontal receive and VV - for vertical transmit and vertical receive. The image coordinates are oriented along the flight direction and the ground range. Geometric projection is in the azimuth-ground range without terrain correction [53]. The images are of high resolution, with a descending angle of $40^{\circ}$ which leads to a higher range and an azimuth pixel spacing of $1 \mathrm{~m}$. Figure 5 and Figure 6 show the recorded water levels and the acquired images according to date.

At Walmsburg Oxbow, the highest water level of $13.58 \mathrm{~m}$ above sea level (asl) was measured on 11 June 2013. During the high flood in January 2011, the highest water level of $13.16 \mathrm{~m}$ asl was measured on 23 January, while, the maximum accessible water level among the TSX images of $12.35 \mathrm{~m}$ asl was acquired on 19 January 2011 for that particular flood. The lowest water level of $6.98 \mathrm{~m}$ asl was measured on 2 September 2012 while the least accessible water level among the TSX images of $7.24 \mathrm{~m}$ asl was acquired on 22 June 2011. All the acquired images were taken in the same descending orbit direction. Therefore, the image acquired on 22 June 2011 was used for determining the pre-flood status, and the image acquired on 19 January 2011 was used for investigating the post-flood status.

At Wehningen Oxbow, the highest water level of $17.02 \mathrm{~m}$ asl was measured on 11 June 2013. During the high flood in January 2011, the highest water level of $16.57 \mathrm{~m}$ asl was measured on 23 January, while the maximum accessible water level among the TSX images of $16.17 \mathrm{~m}$ asl was acquired on 25 January 2011. The lowest water level of $10.59 \mathrm{~m}$ asl was measured on 22 July 2010, while the least accessible water level among the TSX 


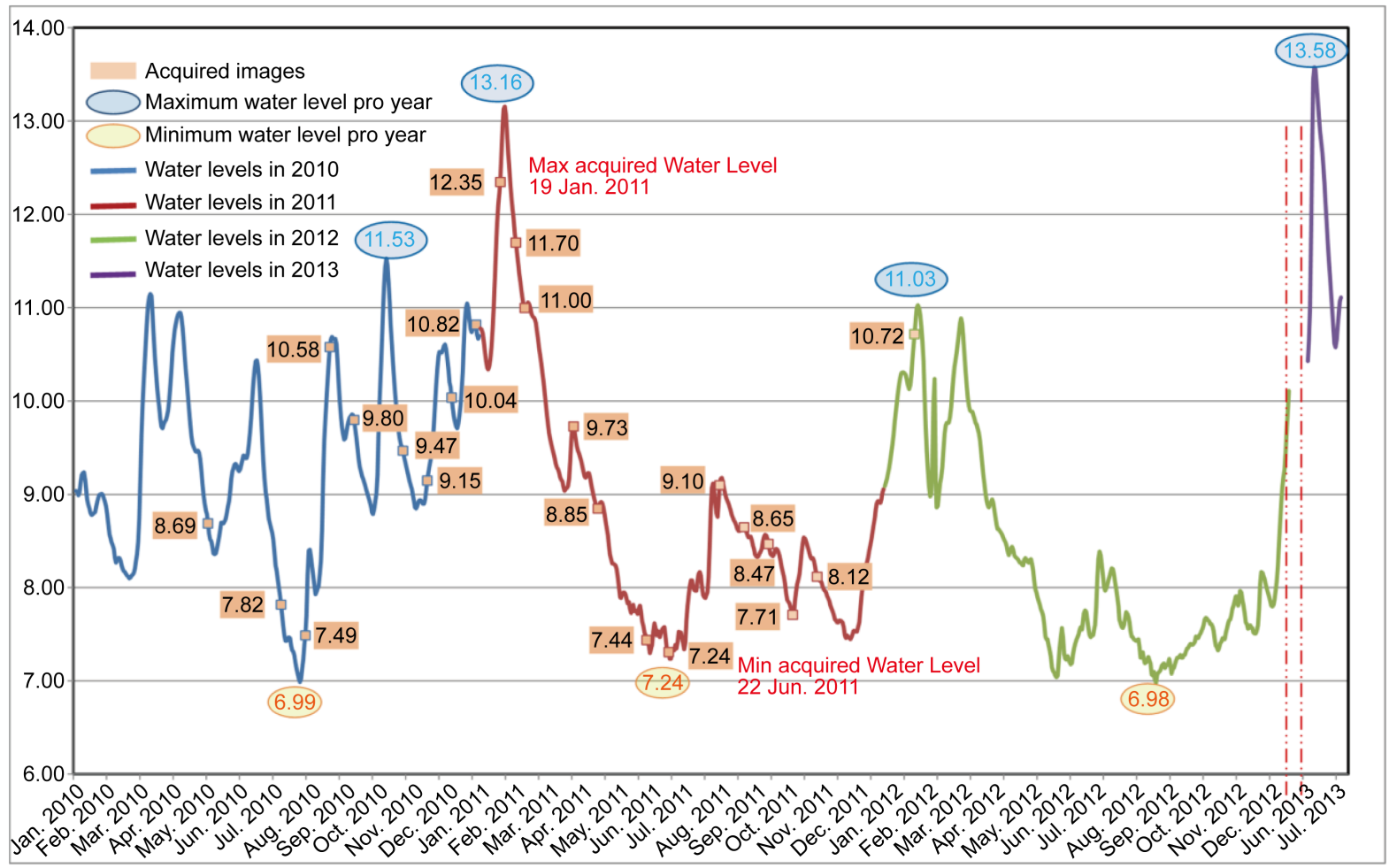

Figure 5. The water levels measured at Neu Darchau gauge around Walmsburg Oxbow from January 2010 to December 2012 in $\mathrm{m}$ above sea level.

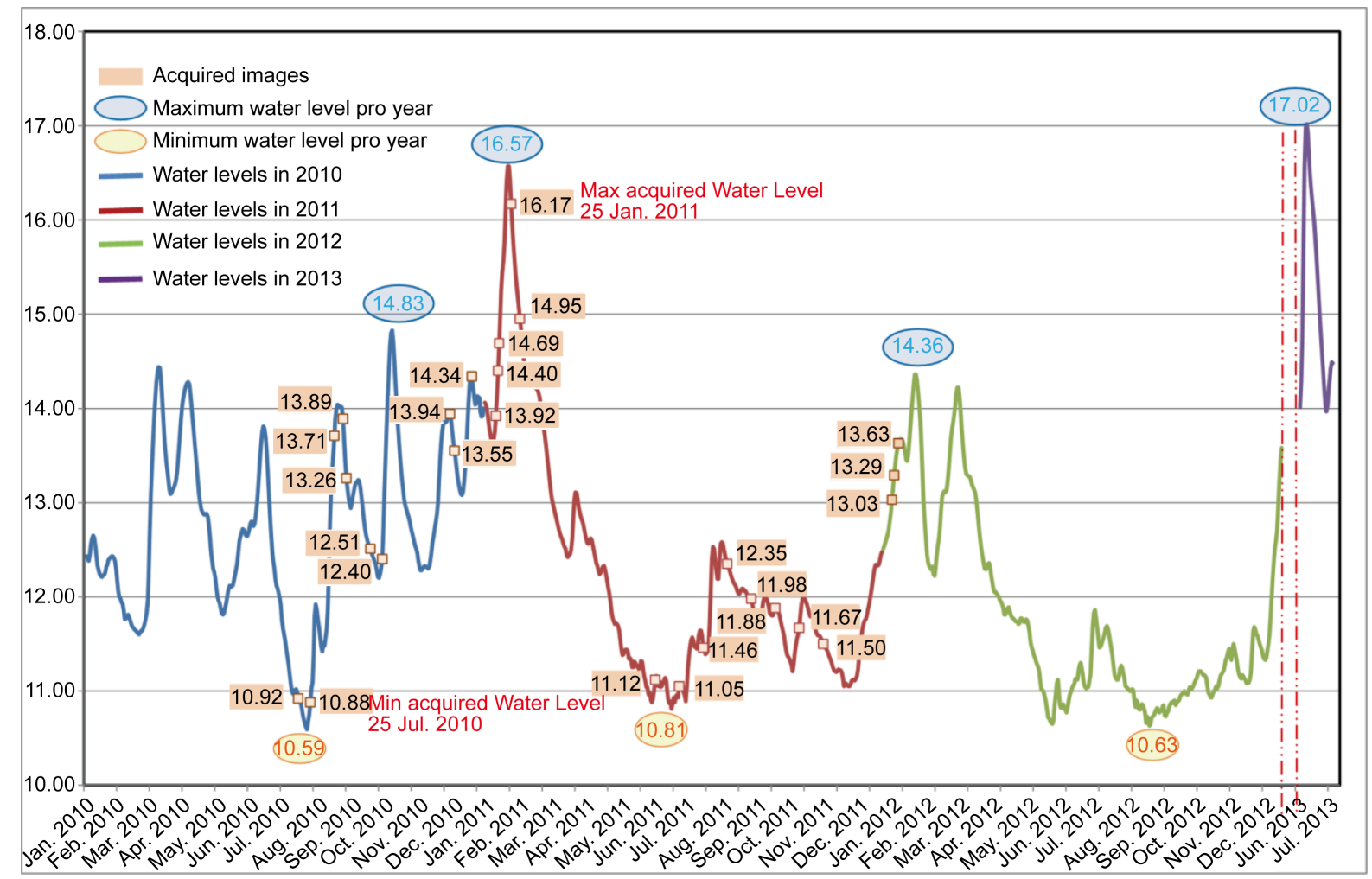

Figure 6. The water levels measured at Damnatz gauge around Wehningen Oxbow from January 2010 to December 2012 in $\mathrm{m}$ above sea level. 
images of $10.88 \mathrm{~m}$ asl was acquired on 25 July 2010. Some of the acquired images were taken in descending orbit direction while others were acquired in the ascending orbit direction. The image acquired on 25 July 2010 was taken in the ascending orbit direction whereas the image acquired on 25 January 2011was taken in the descending orbit direction. It is better to process pre- and post-images with same orbit direction. Hence, another image with low water level was chosen to study the pre-flood status. On 28 June 2011, the image was acquired in the descending orbit direction, and the measured water level was $11.05 \mathrm{~m}$ asl. Therefore, the image acquired on 28 June 2011 was used for determining the pre-flood status, and the image acquired on 25 January 2011 was used for investigating the post-flood status.

For both oxbows, the pre-flood images were used to define land use, while the post-flood images were used in mapping the flooded areas. The land-use/land cover LULC maps and the detection maps were used in evaluating the hazards resulting from the January 2011 flood and to identify the risk zones, as shown in Figure 7. These images must first be processed, and then classified, to generate the LULC maps and detection maps for both areas; subsequently, the risk zones can be defined.

\subsection{Image Processing}

For both study areas, the images with both their acquisitions were coregistered so that relative translational shift and rotational and scale differences could be corrected through performing spatial registration and, potentially, resampling. This was done using the SARSCAPE module of the ENVI program after importing the images as TerraSAR-X standard formats. The coregistered images were geocoded to provide a radiometric calibration and a cartographic reference system. The resultant geocoded images for both the $\mathrm{HH}$ and VV polarizations were stacked together to provide two images for pre-flood and post-flood status at both Walmsburg Oxbow and Wehningen Oxbow. Image rectification and georeference transformation were applied to the four stacked images using ERDAS Imagine 9.3 software. The images were loaded into ERDAS Imagine for data preparation and reprojection. The SAR images were geometrically transformed to the Universal Transverse Mercator (UTM) projection with spheroid WGS 84 and zone 32 North, and resampled into one meter pixel size using the projective transform model under the Geocorrect image Tool. The four images were filtered with the Lee filter in order to remove or decrease speckle noise. The Lee-filter was applied using the ERDAS Imagine software through the Speckle Suppression option under the Radar Interpreter menu. The coefficient of variation for the subset of the geocoded images was calculated for each image. The Lee filter was selected from the list of available filters and the value for the coefficient of variation was inserted. The window size was set to seven pixels.

\subsection{Image Classification}

The object-based classification method investigated for mapping the land-use/land-cover LULC maps for both study areas, as shown in Figure 8. The object-based classification method was processed by the rule-based classifier in the ENVI EX program. The LULC maps initially produced were enhanced using the neighborhood

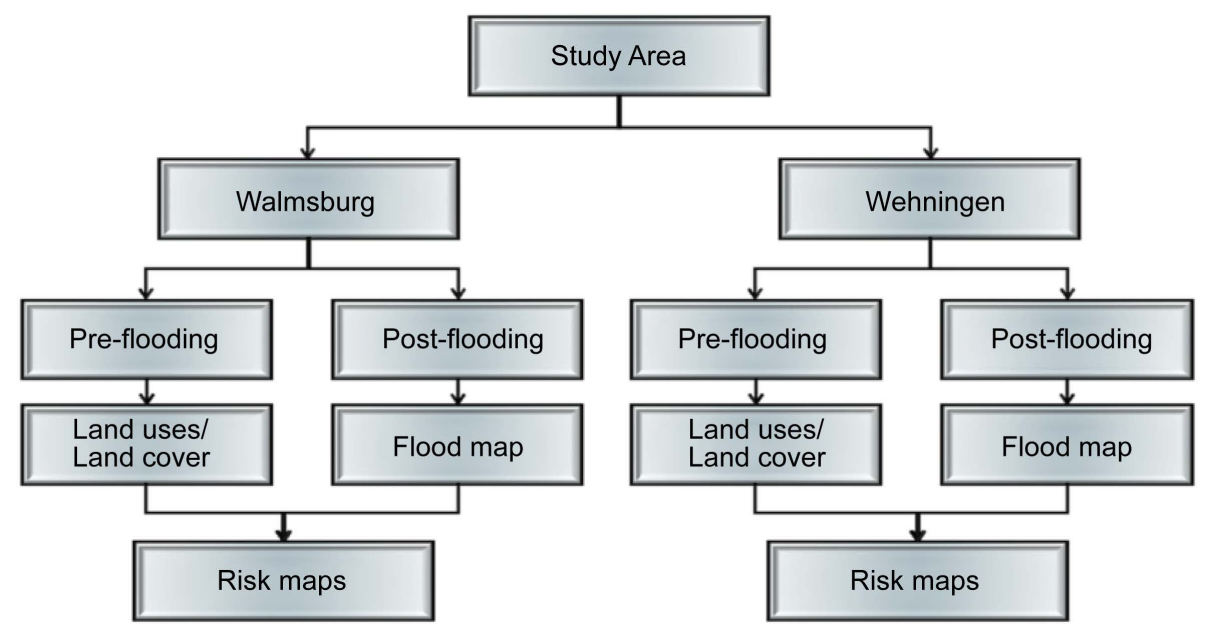

Figure 7. Methodology for identifying the risk zones based on January 2011 flood. 


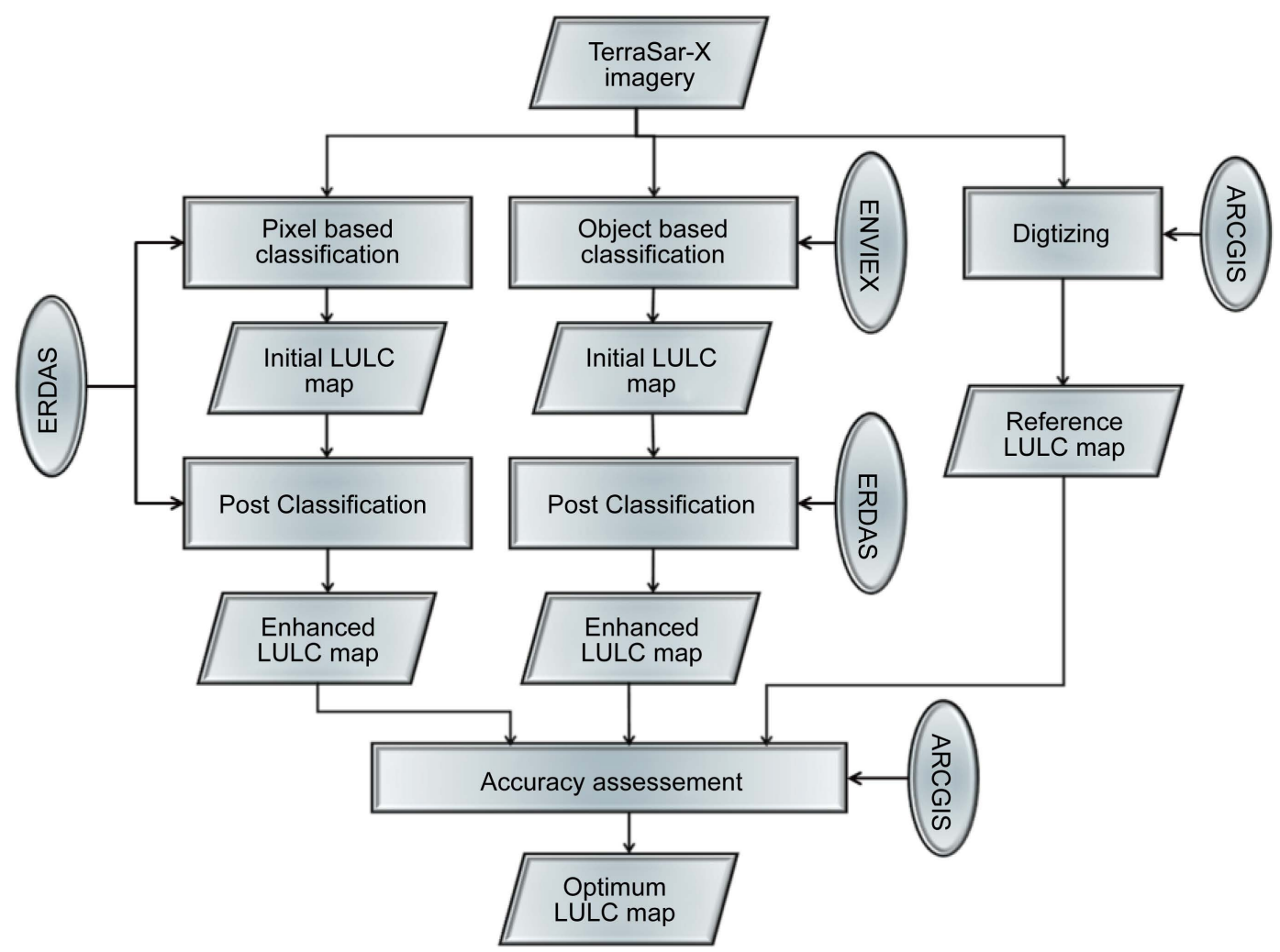

Figure 8. The methodology flow chart for producing LULC maps using pre-flood imagery.

filter. It is difficult to obtain up-to-date reference maps for LULC. The available maps were old and did not accurately represent the current land cover. Therefore, reference LULC maps were digitized from the TSX imagery using the ARCGIS program to assess the classification accuracy, as shown in Figure 9. The resulting enhanced LULC maps were analyzed using the spatial module in ARCGIS through calculating cross-tabulated areas between the digitized and the resultant LULC classifications. The resulting tables were processed in Microsoft Excel to estimate the error matrix (or confusion matrix), which is a method for determining the accuracy of classified classes with respect to the reference data [43]. The results of the object-based classification were compared in order to determine the optimum method for mapping the LULC classification.

As discussed in the introduction, the roughness of a surface affects the backscatter from it. The greater the roughness, the more scattering back to the radar there is, and the lighter the surface appears in radar imagery, leading to variation in the image texture [45]. Image texture measures the relationships between pixels and their neighbors and plays an important role in interpreting SAR imagery, especially high spatial resolution images [43]. SAR imagery has a single band which is based on intensity of grey level formed from radar backscatter, and thus texture is the main source of information used to study land cover and land use in pixel-based analysis [45]. To derive further information beyond the spectral information of SAR imagery, object-oriented image analysis can be used to extract information regarding shape, size and relationship of image objects [43]. Therefore, object-based analysis was used in this study.

Envi EX has a tool that utilizes object-based processing named Feature Extraction. Feature Extraction is a tool for extracting information from high-resolution panchromatic or multispectral imagery based on spatial, spectral, and texture characteristics. It uses an object-based approach to classify imagery. It is a combined process of segmenting an image into regions of pixels, computing attributes for each region to create objects, and classifying the objects (with rule-based or supervised classification) based on those attributes, to extract features. The workflow consists of two main steps: Find Objects and Extract Features. The Find Objects task is subdivided into four steps: Segment, Merge, Refine, and Compute Attributes. During the segmentation process, pixels with similar feature values (brightness, texture, color, shape) are grouped into small objects. During the regionmerging process, small adjacent segments are aggregated into larger, textured areas based on a combination of 


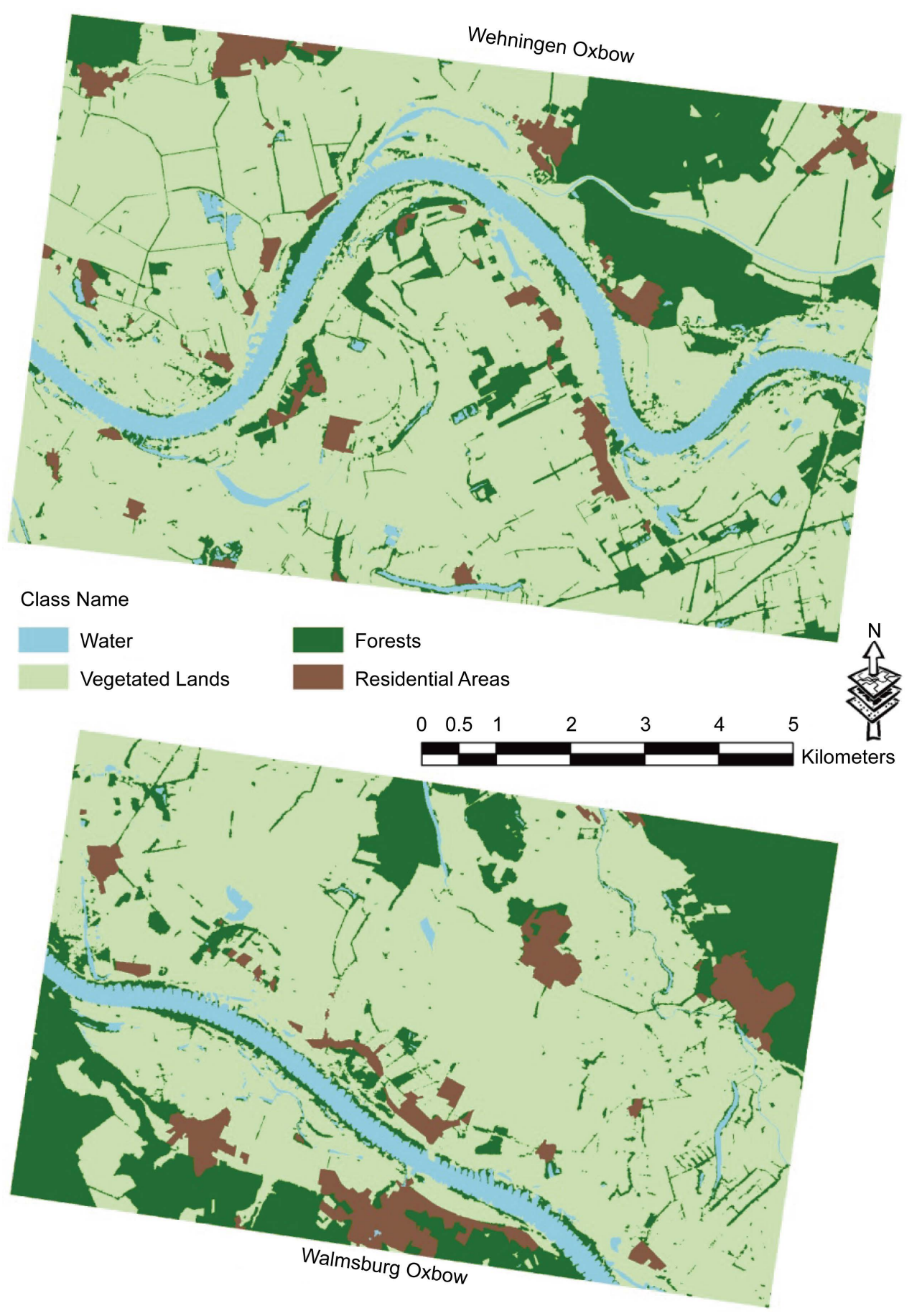

Figure 9. Reference maps for LULC classifications at Wehningen Oxbow and Walmsburg Oxbow.

spectral and spatial information. During the Compute-Attributes process, spatial, spectral, and texture attributes are computed for each object. After completing this task, the Extract Features task can be performed; this consists of supervised or rule-based classification. In the supervised classification process, the training data (samples of known identity) are used to assign objects of unknown identity to one or more known features. The training data can be defined manually or through importing ground truth data in the form of point and polygon shape files. The supervised classifier uses either the K-Nearest-Neighbor method or the Support Vector Machine method. In the rule-based classification process, features are defined by building one or multiple rules based on 
object attributes. This requires human knowledge and reasoning about the extracted features. Finally, the classification results can be exported to shape files and/or raster images [54].

The Decision-Tree method builds classification in the form of a tree structure. The Decision Tree classifier performs multistage classifications by using a series of binary decisions to place pixels or objects into classes. Each decision divides the pixels in a set of images into two classes based on an expression. Each new class can be divided into two more classes based on another expression. As many decision nodes as needed can be utilized. The results of the decisions are classes. The Decision-Tree classification method can be applied to pixel-based classification in the same way as traditional classification algorithms would be applied. It can also be used to generate rules for knowledge-based and object-based classification with different types of attributes [43]. The main features of the LULC map are water, forest, vegetated lands and residential areas. Each feature has different roughness and texture characteristics.

In this research, a Decision-Tree classification algorithm was applied using the rule-based classifier, as shown in Figure 10. The pre-flood images in both study areas were used to identify the land uses. The radar signals returned from water bodies, such as rivers and lakes, have low backscatter. These areas, therefore, are mostly dark on the TSX imagery. The backscatter from forests and residential areas is mainly volume scattering. The backscatter from vegetation-covered areas, such as grasslands, croplands and bare soil fields, depends on the crop types and their distribution on the fields. The scattering from roads is affected by the trees on either side, so they show up as bright lines on radar imagery. In contrast, roads not lined with trees are less visible and may be mistaken for water. Generally, the land cover types in both study areas are complex or mixed, so that different coverages may show similar physical scattering mechanisms. Therefore, the water class and land class were defined in a first step. Then, the land class was isolated and classified as either flat terrain, such as vegetated lands, or uneven terrain, including forests and residential areas. Lastly, the uneven terrain class was detached and further classified as either forest class or residential class. Land classified as vegetated was also subdivided as either cropland or grass; this classification was imported here from previously performed and reported work [55].

The Decision-Tree approach requires comprehensive knowledge of data about the features of the terrain and, furthermore, physical understanding of these. Since each class corresponds to a specific scattering property, decision boundaries were determined based on knowledge acquired experimentally by the analysis of the scattering characteristics of each class. The feature extraction workflow computed spectral, textural, and spatial attributes for the merged objects. In order to locate decision boundaries for separation of the various classes, the histograms of the computed attributes were analyzed to identify peaks, valleys, shoulders, and curvatures. The concepts of natural breaks and clustering were used to define the decision boundaries. Natural breaks and clustering are both methods of manual data classification through dividing data into classes based on natural groups in the data distribution. Natural breaks occur in the histogram at the low points of valley, while cluster divisions occur at the midpoints between peaks or at the shoulders of the histogram [56]. The histograms created for spectral, texture, and spatial characteristics of the TSX imagery were analyzed at the peaks, valleys and shoulders. The effective points which separate classes were employed as decision boundaries, as shown in Figure 11.

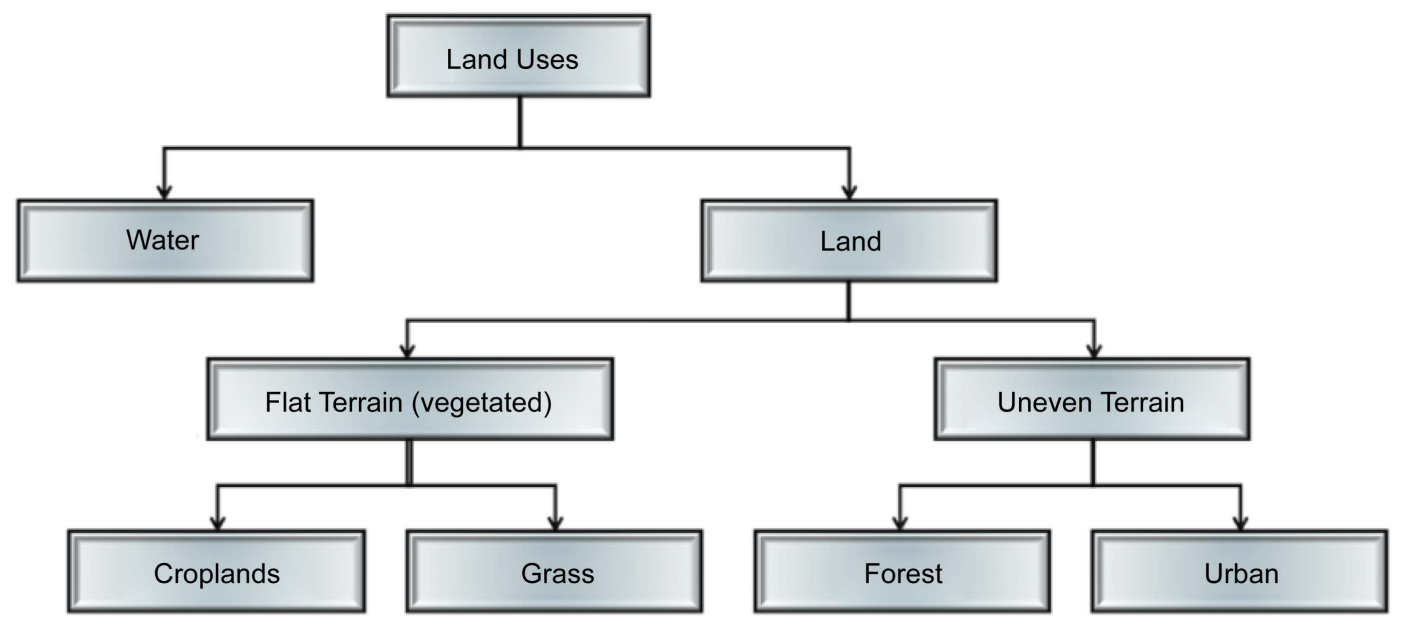

Figure 10. A Decision-Tree classification algorithm for mapping LULC using the pre-flood imagery. 


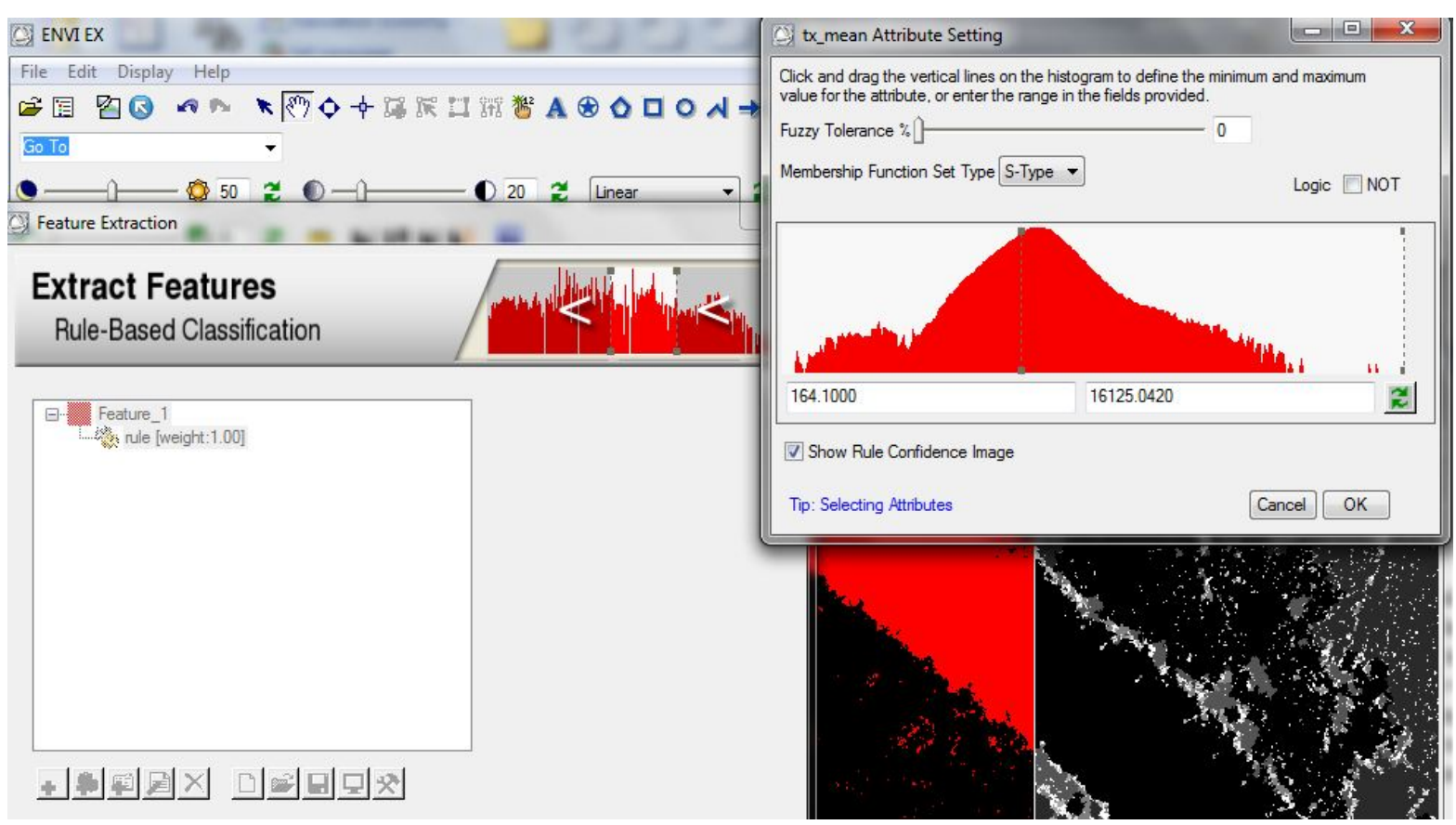

Figure 11. Identifying decision boundaries according to the valley, peak and shoulder of the attributes histogram in the feature extraction workflow under ENVI EX.

For mapping the flood extent areas for both study locations, the optimum classification methods with respect to the LULC classification results were applied. The flood extent maps initially produced were corrected using the digital elevation model (DEM) for this area and the resulting LULC maps. The DEM was used to remove the regions misclassified as water within the area around the river that had a land level higher than the water level measured at the gauges. The LULC maps were used to remove the forest and residential areas which were misclassified as water due to the limitations of $x$-band imagery in mapping the water areas beneath forest and urban coverage [43] [57]. It is difficult to obtain a reference map for extent of a given flood event due to accessibility problems during the flood. Therefore, a reference flood map was digitized from the TSX imagery using the ARCGIS program to assess the classification accuracy. The resulting corrected flood maps were analyzed using the spatial module under ARCGIS to calculate cross-tabulated areas between this digitized reference map and the resulting classifications and subsequently to estimate the confusion matrix for the water class. The flood extent areas generated in 2011 were compared to the flood extent areas for June 2013 created by [58]. Finally, the LULC maps were used in determining if the inundated land was vegetated or residential, and hence in defining the risk zones in January 2011 and June 2013. The results of the classifications produced are presented and explained below.

\section{Results and Discussion}

\subsection{LULC Classification}

For both study areas, the raw and Lee-filtered images were processed to identify the land use classes using the object-based approach. The land uses were delineated manually to evaluate the accuracy of the resulting classification. The reference digitized LULC maps for both study areas have four main classes, as previously stated. The images at Walmsburg Oxbow has 5\% water extent, 66\% vegetated lands, 23\% forests and 6\% residential areas. The images at Wehningen Oxbow has $8 \%$ water extent, $71 \%$ vegetated lands, $17 \%$ forests and $4 \%$ residential areas. In order to generate the rule-based classifications, the workflow for feature extraction in ENVI EX was applied six times for each study area, using $\mathrm{HH}^{-}, \mathrm{VV}-$, and $\mathrm{HH} / \mathrm{VV}-$ polarization of the raw and Lee-filtered images. Three different combinations of class pairs were chosen for feature separation to represent the three branches of the Decision-Tree. These combinations are 1) water and land, 2) vegetated lands and uneven lands, and 3) residential areas and forests. 
For branch (1), 64 classifications were generated to map the water and land classes. From the spectral-attributes, the band-average was used; the mean and variance were used from the texture-attributes; and solidity, convexity, compact and elongation were used from the spatial-attributes. In addition, some rule sets were used to combine certain attributes together to enhance the classification results. Rule set 11 combined the band-average and mean-texture; rule set 12 included texture-mean and solidity-attributes; rule set 13 added the roundness to texture-mean and solidity-attributes; rule set 4 incorporated elongation with texture-mean-attributes, solidity and roundness-attributes. The producer accuracy and the total accuracy are shown in Table 1. For branch (2), the

Table 1. Summary of producer accuracy (\%) for water class and land class (Vegetated Land, Forest, Resedential Areas) applying the object-based procedure.

\begin{tabular}{|c|c|c|c|c|c|c|c|c|c|c|c|}
\hline \multirow{3}{*}{ Polarization } & \multirow{3}{*}{ Rules } & \multirow{3}{*}{$\begin{array}{l}\text { Filter } \\
\text { Type }\end{array}$} & \multicolumn{9}{|c|}{ Producer Accuracy \% } \\
\hline & & & \multicolumn{3}{|c|}{ Wehningen Oxbow } & \multicolumn{3}{|c|}{ Walmsburg Oxbow } & \multicolumn{3}{|c|}{ Average } \\
\hline & & & Water & Land & Total & Water & Land & Total & Water & Land & Total \\
\hline \multirow{4}{*}{$\mathrm{HH}$} & \multirow{2}{*}{ Average Band > 45} & Raw & 86 & 99 & 98 & 92 & 99 & 99 & 89 & 99 & 99 \\
\hline & & Lee & 83 & 94 & 93 & 87 & 99 & 99 & 85 & 97 & 96 \\
\hline & \multirow{2}{*}{ Average Band > 55} & Raw & 92 & 97 & 97 & 94 & 98 & 98 & 93 & 97 & 97 \\
\hline & & Lee & 88 & 92 & 92 & 91 & 99 & 98 & 89 & 95 & 95 \\
\hline \multirow{4}{*}{ VV } & \multirow{2}{*}{ Average Band > 45} & Raw & 87 & 99 & 98 & 91 & 99 & 99 & 89 & 99 & 99 \\
\hline & & Lee & 84 & 94 & 93 & 87 & 99 & 99 & 85 & 97 & 96 \\
\hline & \multirow{2}{*}{ Average Band > 55} & Raw & 92 & 95 & 95 & 94 & 98 & 98 & 93 & 97 & 96 \\
\hline & & Lee & 89 & 90 & 90 & 90 & 97 & 97 & 90 & 93 & 93 \\
\hline \multirow{24}{*}{ HH/VV } & \multirow{2}{*}{ Average Band } & Raw & 92 & 97 & 97 & 94 & 98 & 97 & 93 & 97 & 97 \\
\hline & & Lee & 90 & 89 & 89 & 92 & 97 & 97 & 91 & 93 & 93 \\
\hline & \multirow{2}{*}{ Rule Set 11} & Raw & 92 & 98 & 97 & 94 & 98 & 97 & 93 & 98 & 97 \\
\hline & & Lee & 88 & 92 & 92 & 92 & 97 & 97 & 90 & 95 & 95 \\
\hline & \multirow{2}{*}{ Texture Mean > 55} & Raw & 92 & 98 & 97 & 94 & 98 & 98 & 93 & 98 & 98 \\
\hline & & Lee & 88 & 93 & 92 & 90 & 99 & 98 & 89 & 96 & 95 \\
\hline & \multirow{2}{*}{ Texture Variance } & Raw & 87 & 99 & 98 & 84 & 99 & 99 & 86 & 99 & 98 \\
\hline & & Lee & 77 & 94 & 93 & 68 & 99 & 98 & 72 & 97 & 96 \\
\hline & \multirow{2}{*}{ Texture Mean > 45} & Raw & 84 & 99 & 99 & 94 & 98 & 98 & 89 & 99 & 98 \\
\hline & & Lee & 83 & 94 & 93 & 90 & 99 & 98 & 86 & 97 & 96 \\
\hline & \multirow{2}{*}{ Solidity } & Raw & 65 & 99 & 97 & 74 & 99 & 98 & 69 & 99 & 98 \\
\hline & & Lee & 38 & 95 & 90 & 68 & 99 & 98 & 53 & 97 & 94 \\
\hline & \multirow{2}{*}{ Convexity } & Raw & 64 & 49 & 50 & 99 & 62 & 64 & 82 & 56 & 57 \\
\hline & & Lee & 68 & 88 & 86 & 68 & 84 & 83 & 68 & 86 & 85 \\
\hline & \multirow{2}{*}{ Compact } & Raw & 64 & 99 & 97 & 72 & 99 & 97 & 68 & 99 & 97 \\
\hline & & Lee & 74 & 87 & 86 & 68 & 99 & 98 & 71 & 93 & 92 \\
\hline & \multirow{2}{*}{ Elongation } & Raw & 76 & 26 & 29 & 73 & 99 & 99 & 74 & 63 & 64 \\
\hline & & Lee & 77 & 95 & 94 & 69 & 99 & 98 & 73 & 98 & 96 \\
\hline & \multirow{2}{*}{ Rule Set 12} & Raw & 85 & 99 & 98 & 92 & 99 & 99 & 88 & 99 & 99 \\
\hline & & Lee & 83 & 94 & 93 & 87 & 99 & 99 & 85 & 97 & 96 \\
\hline & \multirow{2}{*}{ Rule Set 13} & Raw & 87 & 98 & 97 & 92 & 99 & 99 & 90 & 98 & 98 \\
\hline & & Lee & 84 & 94 & 93 & 87 & 99 & 99 & 85 & 97 & 96 \\
\hline & \multirow{2}{*}{ Rule Set 14} & Raw & 82 & 94 & 93 & 86 & 99 & 98 & 84 & 97 & 96 \\
\hline & & Lee & 82 & 94 & 93 & 82 & 99 & 99 & 82 & 97 & 96 \\
\hline
\end{tabular}


land class mask was used to isolate the land areas from each image. The masked images were used in generating different classifications for the vegetated land and uneven land classes. 52 classifications were generated to map the vegetated lands and uneven lands. From the spectral-attributes, the band-average was used; the mean, variance and entropy were used from the texture-attributes; and area, solidity, convexity, compact, elongation and roundness were used from the spatial-attributes. In addition, one rule set was used to combine the band-average and mean-texture. The producer accuracy and the total accuracy are summarized in Table 2. For branch (3), the uneven land class mask was used to isolate the uneven lands from each image. The masked images were used in generating different classifications for the residential area and forest classes. 44 classifications were generated to

Table 2. Summary of the producer accuracy (\%) for Vegetated Land and Uneven Land classes (Forest, Residential Areas) applying the object-based procedure.

\begin{tabular}{|c|c|c|c|c|c|c|c|c|c|c|c|}
\hline \multirow[b]{3}{*}{ Polarization } & \multirow[b]{3}{*}{ Rules } & \multirow{3}{*}{$\begin{array}{l}\text { Filter } \\
\text { Type }\end{array}$} & \multicolumn{9}{|c|}{ Producer Accuracy \% } \\
\hline & & & \multicolumn{3}{|c|}{ Wehningen Oxbow } & \multicolumn{3}{|c|}{ Walmsburg Oxbow } & \multicolumn{3}{|c|}{ Average } \\
\hline & & & $\begin{array}{l}\text { Vegetated } \\
\text { Land }\end{array}$ & $\begin{array}{l}\text { Uneven } \\
\text { Land }\end{array}$ & Total & $\begin{array}{l}\text { Vegetated } \\
\text { Land }\end{array}$ & $\begin{array}{l}\text { Uneven } \\
\text { Land }\end{array}$ & Total & $\begin{array}{l}\text { Vegetated } \\
\text { Land }\end{array}$ & $\begin{array}{l}\text { Uneven } \\
\text { Land }\end{array}$ & Total \\
\hline \multirow{2}{*}{$\mathrm{HH}$} & \multirow{2}{*}{ Average Band } & Raw & 80 & 59 & 75 & 87 & 63 & 80 & 83 & 61 & 77 \\
\hline & & Lee & 87 & 67 & 83 & 90 & 48 & 79 & 90 & 58 & 81 \\
\hline \multirow{2}{*}{ VV } & \multirow{2}{*}{ Average Band } & Raw & 86 & 40 & 76 & 85 & 52 & 75 & 86 & 46 & 75 \\
\hline & & Lee & 88 & 64 & 82 & 88 & 46 & 75 & 88 & 55 & 79 \\
\hline \multirow{22}{*}{$\mathrm{HH} / \mathrm{VV}$} & \multirow{2}{*}{ Average Band } & Raw & 80 & 62 & 76 & 80 & 64 & 75 & 80 & 63 & 75 \\
\hline & & Lee & 87 & 68 & 83 & 85 & 72 & 81 & 86 & 70 & 82 \\
\hline & \multirow{2}{*}{ Rule Set 21} & Raw & 80 & 54 & 74 & 80 & 64 & 75 & 80 & 59 & 75 \\
\hline & & Lee & 87 & 56 & 79 & 86 & 51 & 75 & 86 & 53 & 77 \\
\hline & \multirow{2}{*}{ Texture Mean } & Raw & 80 & 58 & 75 & 82 & 76 & 73 & 81 & 67 & 74 \\
\hline & & Lee & 88 & 61 & 82 & 83 & 67 & 79 & 86 & 64 & 80 \\
\hline & \multirow{2}{*}{ Texture Variance } & Raw & 80 & 74 & 77 & 76 & 71 & 74 & 78 & 72 & 75 \\
\hline & & Lee & 92 & 76 & 88 & 86 & 74 & 84 & 89 & 75 & 86 \\
\hline & \multirow{2}{*}{ Solidity } & Raw & 81 & 56 & 75 & 87 & 50 & 75 & 84 & 53 & 75 \\
\hline & & Lee & 75 & 58 & 70 & 80 & 44 & 69 & 77 & 51 & 70 \\
\hline & \multirow{2}{*}{ Convexity } & Raw & 80 & 43 & 71 & 84 & 48 & 73 & 82 & 45 & 72 \\
\hline & & Lee & 86 & 63 & 80 & 81 & 56 & 74 & 84 & 60 & 77 \\
\hline & \multirow{2}{*}{ Compact } & Raw & 80 & 52 & 74 & 87 & 35 & 71 & 84 & 43 & 72 \\
\hline & & Lee & 86 & 61 & 80 & 74 & 55 & 68 & 80 & 58 & 74 \\
\hline & \multirow{2}{*}{ Elongation } & Raw & 87 & 68 & 82 & 85 & 66 & 80 & 86 & 67 & 81 \\
\hline & & Lee & 86 & 57 & 79 & 88 & 51 & 77 & 87 & 54 & 78 \\
\hline & \multirow{2}{*}{ Area } & Raw & 85 & 47 & 76 & 80 & 35 & 66 & 82 & 41 & 71 \\
\hline & & Lee & 88 & 68 & 84 & 86 & 65 & 80 & 87 & 66 & 82 \\
\hline & \multirow{2}{*}{ Round } & Raw & 79 & 53 & 73 & 77 & 64 & 73 & 78 & 58 & 73 \\
\hline & & Lee & 92 & 38 & 79 & 86 & 50 & 75 & 89 & 44 & 77 \\
\hline & \multirow{2}{*}{ Texture Entropy } & Raw & 87 & 59 & 76 & 77 & 62 & 72 & 82 & 60 & 74 \\
\hline & & Lee & 91 & 77 & 87 & 87 & 81 & 84 & 89 & 79 & 86 \\
\hline
\end{tabular}


map the forests and residential areas. From the spectral attributes, the band average was used, the mean, variance and entropy were used from the texture-attributes; and solidity, convexity, rectangle fit and roundness were used from the spatial-attributes. In addition, one rule set was used to combine the band-average and texture-mean attributes. The producer accuracy and the total accuracy are summarized in Table 3.

As shown in Tables 1-3, using dual-polarization HH/VV led to higher total producer accuracy than the total producer accuracies employing either $\mathrm{HH}^{-}$or $\mathrm{VV}-$ polarization only. In contrast to the vegetated/uneven land classification results, using raw images facilitated higher producer accuracies than the Lee-filtered images in the results of both land/water and forests/residential classifications. The most useful features for separating the water class from the land class were texture-mean and band-average. Other attributes are not efficient in separating water from land. Applying either rule set 11 or texture-mean attributes enabled slightly better producer accuracy for the land class than employing the average band attributes. The best producer accuracy for the water class was 94\% using the raw images with either single or dual polarization based on the average-band-attribute and texture-mean-attribute rules at Walmsburg Oxbow, while the lowest producer accuracy, of only 38\%, was achieved at Wahgingen Oxbow when using Lee-filter images based on the convexity-attribute rule. The best total producer accuracy was $99 \%$, using the raw images with single or dual polarization based on many rules at Walmsburg

Table 3. Summary of producer accuracy (\%) for the Forest and Residential Area classes applying the object-based procedure.

\begin{tabular}{|c|c|c|c|c|c|c|c|c|c|c|c|}
\hline \multirow[b]{3}{*}{ Polarization } & \multirow[b]{3}{*}{ Rules } & \multirow{3}{*}{$\begin{array}{l}\text { Filter } \\
\text { Type }\end{array}$} & \multicolumn{9}{|c|}{ Producer Accuracy \% } \\
\hline & & & \multicolumn{3}{|c|}{ Wehningen Oxbow } & \multicolumn{3}{|c|}{ Walmsburg Oxbow } & \multicolumn{3}{|c|}{ Average } \\
\hline & & & Forests & $\begin{array}{l}\text { Residential } \\
\text { Areas }\end{array}$ & Total & Forests & $\begin{array}{l}\text { Residential } \\
\text { Araes }\end{array}$ & Total & Forests & $\begin{array}{l}\text { Residential } \\
\text { Araes }\end{array}$ & Total \\
\hline \multirow{2}{*}{$\mathrm{HH}$} & \multirow{2}{*}{ Average Band } & Raw & 86 & 63 & 82 & 79 & 60 & 76 & 83 & 62 & 79 \\
\hline & & Lee & 85 & 45 & 78 & 78 & 34 & 68 & 82 & 40 & 73 \\
\hline \multirow{2}{*}{ VV } & \multirow{2}{*}{ Average Band } & Raw & 85 & 76 & 82 & 81 & 73 & 77 & 83 & 75 & 80 \\
\hline & & Lee & 83 & 53 & 78 & 76 & 45 & 69 & 80 & 49 & 74 \\
\hline \multirow{18}{*}{$\mathrm{HH} / \mathrm{VV}$} & \multirow{2}{*}{ Average Band } & Raw & 84 & 76 & 83 & 81 & 74 & 80 & 83 & 75 & 82 \\
\hline & & Lee & 83 & 53 & 77 & 79 & 48 & 72 & 81 & 51 & 75 \\
\hline & \multirow{2}{*}{ Rule Set 31} & Raw & 85 & 76 & 83 & 82 & 75 & 80 & 84 & 76 & 82 \\
\hline & & Lee & 83 & 52 & 77 & 79 & 50 & 75 & 81 & 51 & 76 \\
\hline & \multirow{2}{*}{ Texture Mean } & Raw & 83 & 78 & 82 & 80 & 75 & 79 & 82 & 77 & 81 \\
\hline & & Lee & 75 & 60 & 72 & 76 & 59 & 70 & 76 & 60 & 71 \\
\hline & \multirow{2}{*}{ Texture Variance } & Raw & 61 & 52 & 59 & 11 & 71 & 27 & 36 & 62 & 43 \\
\hline & & Lee & 64 & 59 & 62 & 66 & 43 & 69 & 65 & 51 & 66 \\
\hline & \multirow{2}{*}{ Texture Entropy } & Raw & 71 & 69 & 71 & 68 & 56 & 66 & 70 & 63 & 69 \\
\hline & & Lee & 68 & 38 & 62 & 86 & 26 & 73 & 77 & 32 & 68 \\
\hline & \multirow{2}{*}{ Solidity } & Raw & 70 & 65 & 69 & 86 & 39 & 76 & 78 & 52 & 73 \\
\hline & & Lee & 85 & 23 & 77 & 77 & 27 & 67 & 81 & 25 & 72 \\
\hline & \multirow{2}{*}{ Convexity } & Raw & 40 & 73 & 46 & 53 & 54 & 53 & 47 & 64 & 50 \\
\hline & & Lee & 44 & 63 & 48 & 58 & 49 & 56 & 51 & 56 & 52 \\
\hline & \multirow{2}{*}{ Rectangle-fit } & Raw & 89 & 50 & 82 & 80 & 48 & 76 & 85 & 49 & 79 \\
\hline & & Lee & 75 & 38 & 68 & 79 & 24 & 67 & 77 & 31 & 68 \\
\hline & \multirow{2}{*}{ Round } & Raw & 46 & 74 & 53 & 78 & 35 & 69 & 62 & 60 & 61 \\
\hline & & Lee & 62 & 40 & 58 & 84 & 18 & 70 & 73 & 29 & 64 \\
\hline
\end{tabular}


Oxbow, while the lowest total producer accuracy of only 50\% was achieved, again at Wehningen Oxbow, using the Lee-filter images based on the convexity-attribute rule.

The objects misclassified into the water class corresponded to the shadow of the forest areas. The shadow areas have less texture-mean than the water areas of the Elbe River. Therefore, rule set 12 was applied with a lower texture-mean value to isolate the main river, as shown in Figure 12. Figure 12(A) shows the TSX imagery at Wehningen Oxbow. Figure 12(B) shows the land class in yellow, based on a texture means greater than 55. Several areas of the forest shadow which were misclassified as water are circled. Figure 12(C) shows the land class in green based on a texture mean greater than 45 . Several water areas which were misclassified as land are circled. Figure 12(D) shows the land class, in red, based on rule set 13. Several water areas which were correctly re-classified as water are circled. Using the solidity-attribute in rule set 12 improved the water class by $1 \%$. Moreover, the roundness-attribute improved the water class by $2 \%$ in rule set 13 . On the other hand, employing more attributes, such as elongation and length, failed to enhance the water class results and led to lower producer accuracies.

The most useful features for separating vegetated lands class from the uneven lands class were, first, texture-entropy, followed by texture-variance and band-average, respectively. Elongation and area spatial-attributes succeeded to a certain degree in differentiating the two classes. Other attributes were only negligibly successful in separating them. Applying rule set 21, led to less total producer accuracy than employing the band-averageattributes. The elongation-attribute rule enabled better classification results for raw imagery while the textureentropy-rule enabled higher classification accuracy for Lee-filtered images. The greatest producer accuracy for vegetated lands class was 92\%, using the Lee-filtered dual-polarized images at Wehningen Oxbow based on the texture-variance-rule, while the lowest producer accuracy, of only 74\%, was achieved at Walmsburg Oxbow

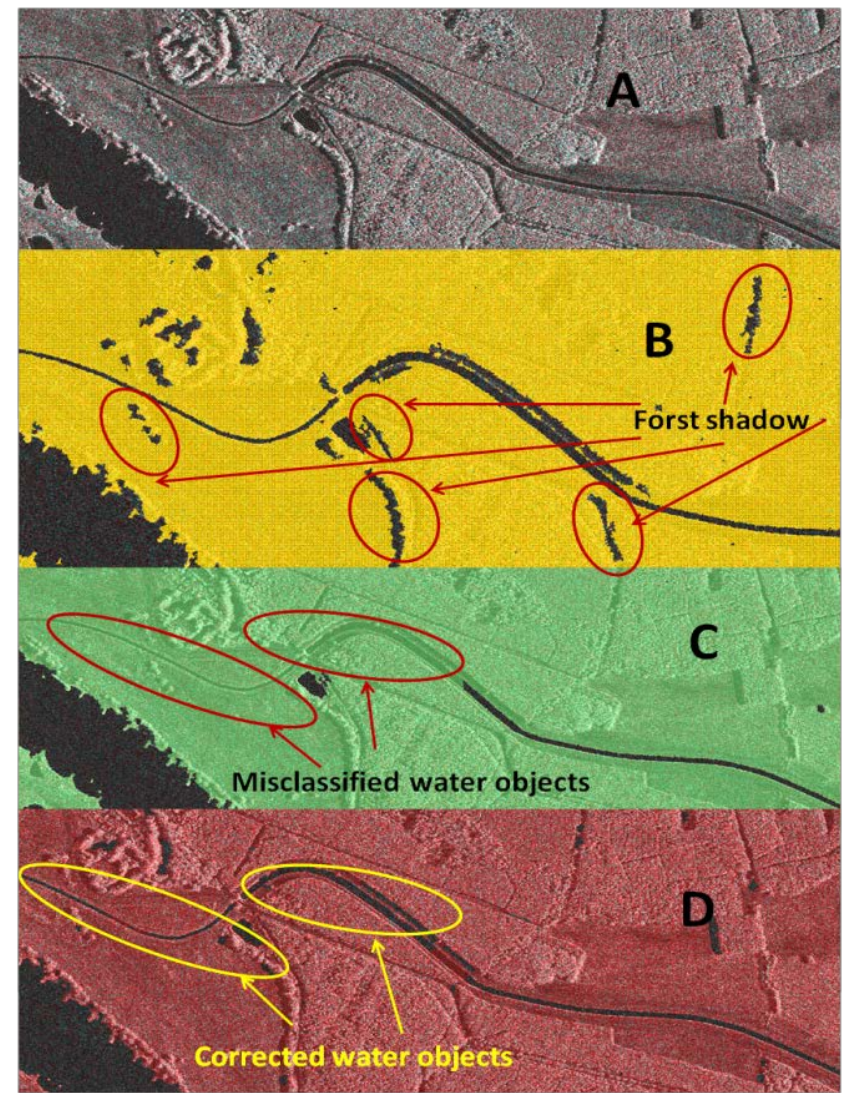

Figure 12. (A) The dual polarization TSX imagery at Wahgingen Oxbow; (B) Land class produced based on texture mean greater than 55 and the forest shadows which are misclassified as water; (C) Land class produced based on texture mean greater than 45 and several water areas which are misclassified as land; (D) Land class produced based on rule set 13 and several water areas which are corrected and classified as water. 
using the Lee-filtered images based on the compact-attribute rule. The maximum producer accuracy for the uneven land class was $81 \%$, using the Lee-filtered dual-polarized images at Walmsburg Oxbow based on the texture-entropy-rule, while the lowest producer accuracy of only $35 \%$ was achieved at same study area, again when using the raw images based on the compact-attribute-rule. The best total producer accuracy was $88 \%$, using Lee-filtered images at Wagingen Oxbow based also on texture-variance-rule, while the lowest total producer accuracy, of only 66\%, was achieved once more at Walmsburg Oxbow using raw images based on the area-attribute-rule. The objects misclassified as vegetated lands in the uneven land class mostly correspond to existing vegetated areas within the residential areas (e.g. parks or gardens), as shown in Figure 13. Figure 13(A) shows the TSX imagery at Wehningen Oxbow. Figure 13(B) shows the uneven land class produced at the same position based on texture-entropy overlaid on the TSX image in red. Figure 13(C) shows the reference map at the same position for the uneven land class, in red, and vegetated lands class, in green. Here, for the uneven land class, it is difficult to separate vegetated areas from buildings within the residential areas. In general, the vegetated areas comprise $15 \%$ to $30 \%$ of the residential areas in the cities and the villages. Therefore the producer accuracy of the uneven land class was limited to about $80 \%$. Nonetheless, the classification has higher accuracy with more details than the reference map.

The effective features for separating the forest class from the residential area class were texture-mean, bandaverage, and their combination in rule set 31. Other attributes were not able to differentiate the two classes. Applying rule set 31 led to slightly better total producer accuracy than employing the band-average-attribute or texture-mean attribute individually. This rule set produced the highest classification accuracy for both raw and Lee-filtered images. The greatest producer accuracy for the forest class was $89 \%$, using the dual-polarized raw images at Wehningen Oxbow based on the rectangle-fit rule, while the lowest producer accuracy, of only 11\%, was achieved at Walmsburg Oxbow using raw images based on the texture-variance-attribute rule. The best producer accuracy for the residential area class was $78 \%$, using the dual-polarized raw images at Wehningen

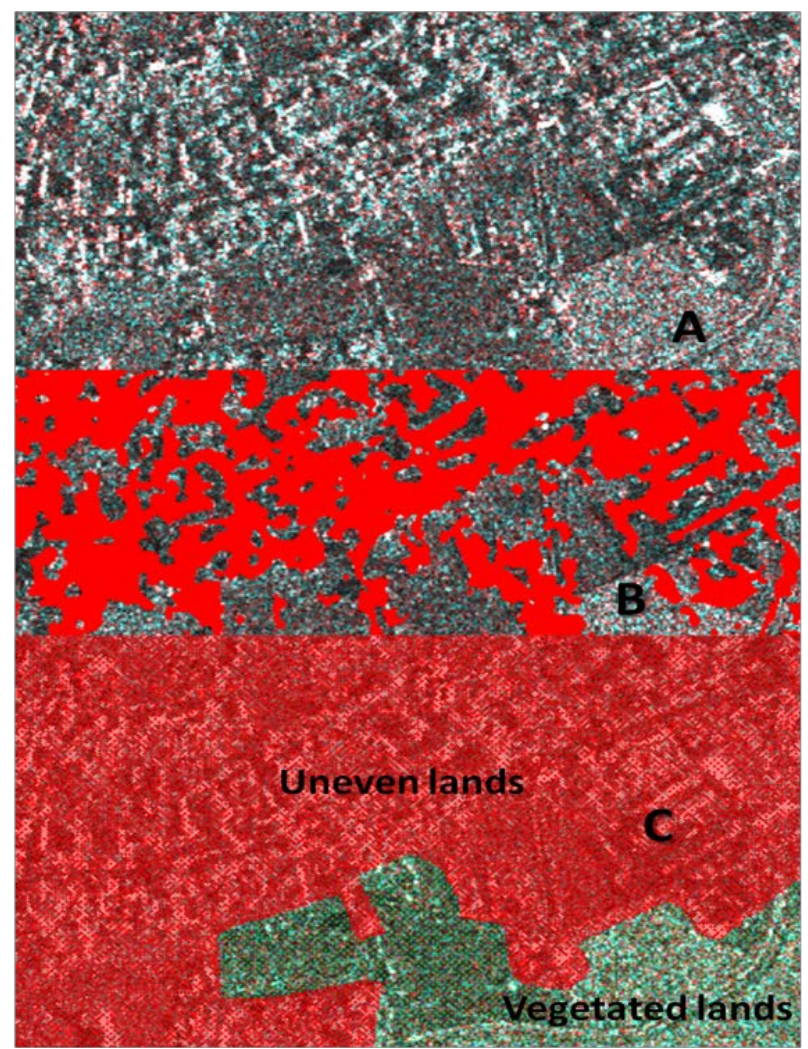

Figure 13. (A) The dual polarization TSX imagery at Wehningen Oxbow; (B) Uneven land class produced at the same position based on texture entropy overlaid on the TSX image in red; (C) The reference map at the same position for the uneven land class (in red) and the vegetated land class (green). 
Oxbow based on the texture-mean-attribute rule, while the lowest producer accuracy of only $23 \%$ was achieved at the same study area using the Lee-filtered images based on the solidity-attribute rule. The highest total producer accuracy was 83\%, using the raw images at Wehningen Oxbow based on the average-band-attributes rule, while the lowest total producer accuracy, of only 27\%, was achieved at Walmsburg Oxbow using the raw imagery based on the text-variance-attribute rule. The objects misclassified as forests in the residential area class correspond to vegetated areas within the residential areas, as shown in Figure 13. Therefore, the producer accuracy of the residential area class was limited to about $78 \%$. Based on the classification results from the three branches, the ultimate Decision-Tree for identifying the major land uses using the raw imagery is shown in Figure 14.

\subsection{Flood Detection Maps}

Based on the LULC classifications results for identifying water areas, using the average band attribute and/or the texture-mean attribute in the rule-based classifier enabled identification of about $90 \%$ of the water cover. Therefore, post-flood images in January 2011 were processed to be used as the pre-flood ones, and classified using the rule-based classifier with the average-band attribute and the texture-mean-attribute. The initial flood extent areas were corrected using the DEM and the LULC maps. The confusion matrices for both areas before and after post-classification are shown in summary in Table 4.

In Table 4, the NH enhancement method refers to the producer accuracies obtained by applying the neighborhood filter, and the residential method refers to the producer accuracies resulting from correcting for areas misclassified as water within the residential area; the forest method refers to the producer accuracies resulting from correcting areas misclassified as water within the forests, while the LULC method means those producer accuracies obtained by correcting areas misclassified as water within the forest and residential areas. In addition, the DEM method gives the producer accuracies after correcting the areas misclassified as water at altitude higher than the gauge water level for this area around the river. The LULC \& DEM method provides the producer accuracies when corrected according to both DEM and LULC. As Table 4 reveals, the results of the rule-based classifier using the texture-mean attribute presented slightly higher total producer accuracies than the rule-based classifier with the average-band attribute. Using the Lee-filtered images led to lower producer accuracies for the water class. Correcting areas misclassified as water within the residential areas enhanced the total producer accuracy by about $0.1 \%$, while correcting areas misclassified as water within the forest resulted in an increase in the land producer accuracy of about $1.5 \%$ and, consequently, in the total producer accuracy of about $1 \%$. On the other hand, the DEM method did not improve the classification results, and consequently the combined LULC \& DEM method only had results similar to the LULC enhancement method alone.

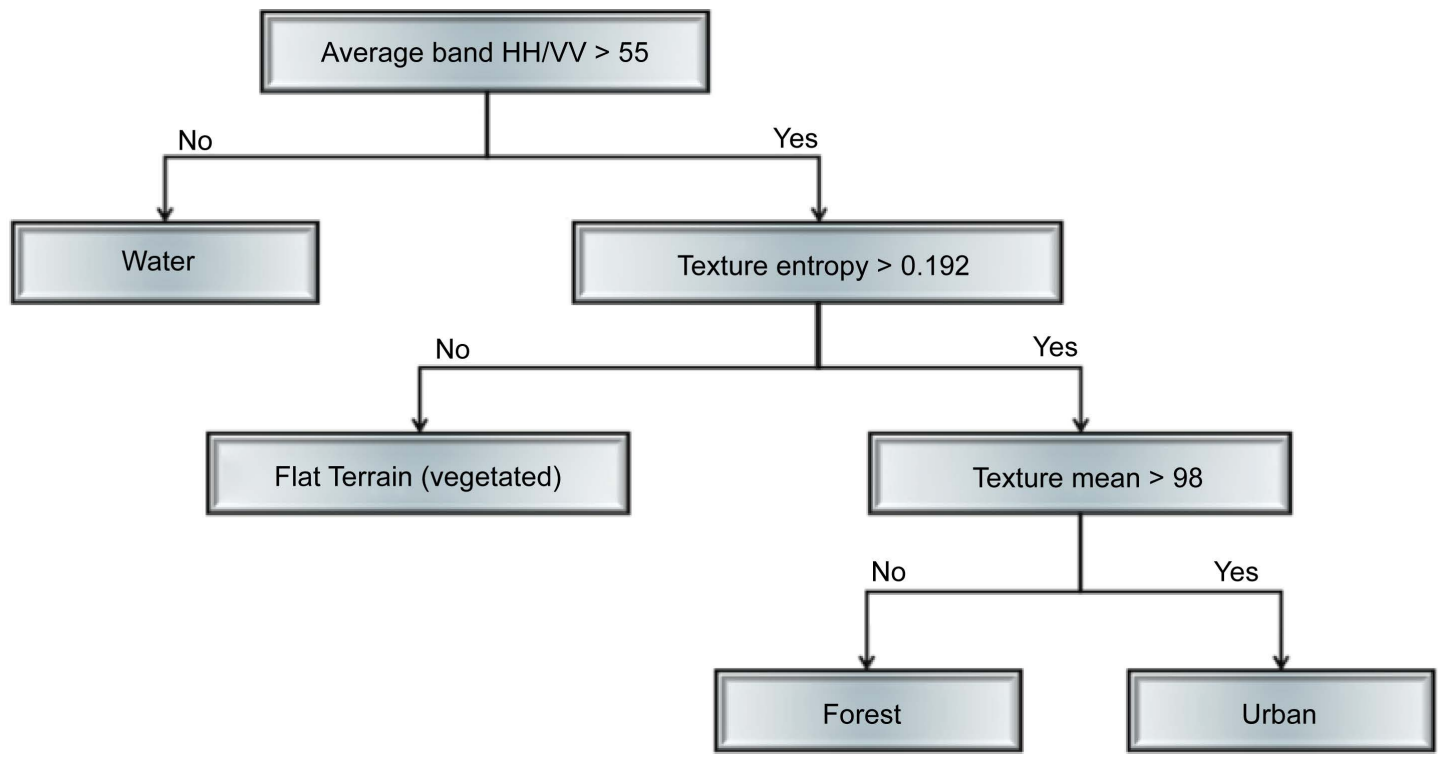

Figure 14. Suggested Decision-Tree classification algorithm for mapping LULC using pre-flood raw imagery. 
Table 4. Summary of producer accuracy (\%) for water and land classes applying the object-based procedure for post-flood imagery.

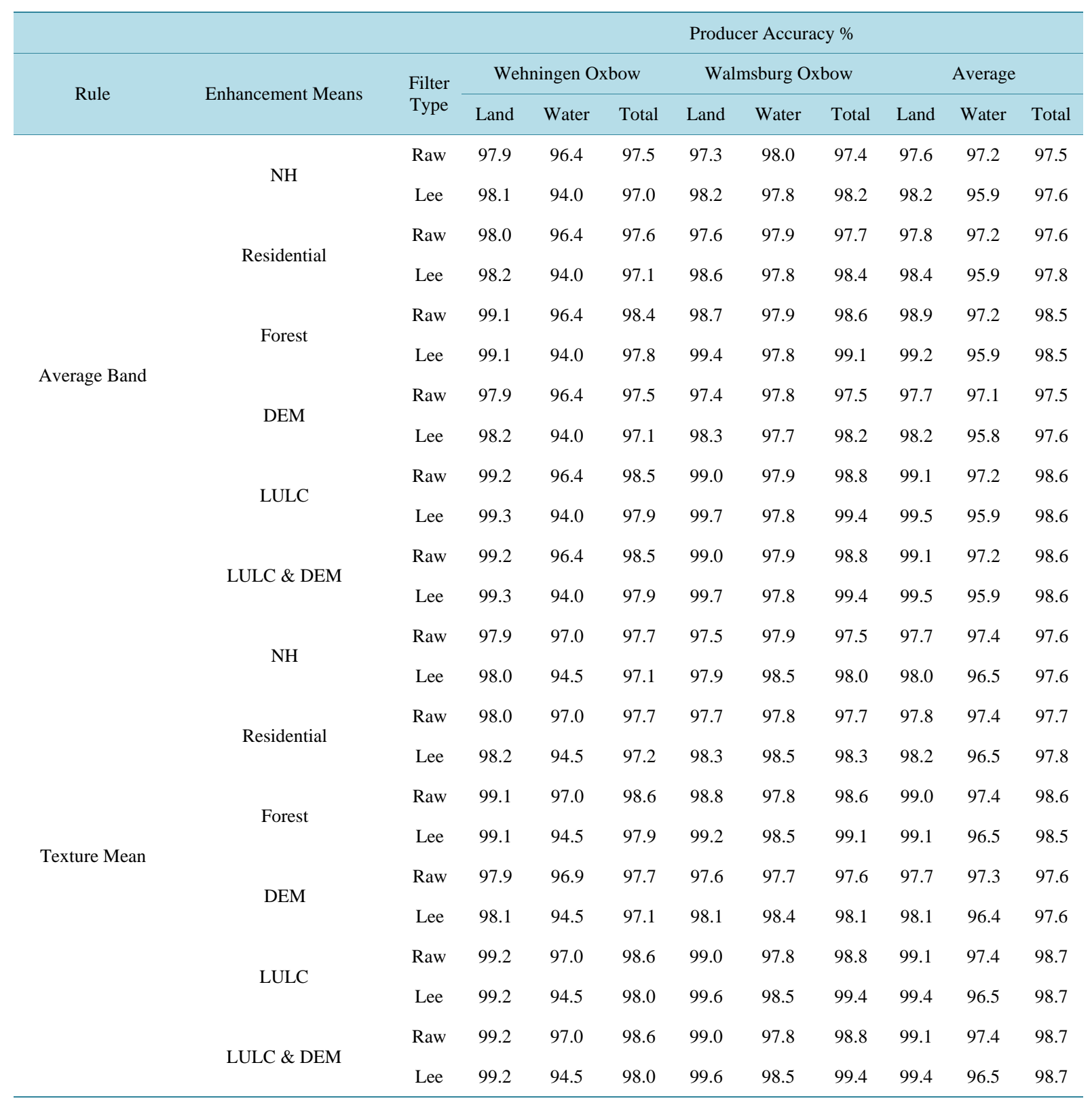

\subsection{Hazard Areas during the Floods of 2011 and 2013}

The flood detection maps produced for January 2011 were compared to the flood extent areas in June 2013 as represented by DLR (2013), and to the high flood zone maps. The flood extent areas were approximately identical for 2011 and 2013 floods, as shown in Figure 15 and Figure 16. Therefore, the flooded areas as shown in the maps produced for 2011 were used in defining the hazard areas for the winter flood in January 2011 and the summer flood in June 2013. The reference LULC maps, and the agricultural land use maps during the summer of 2011, produced by Farghaly et al. (2014), were overlaid onto the flooded areas identified for January 2011 in order to determine the hazard areas, as also shown in Figure 15 and Figure 16.

Figure 15 was used to study the area around Walmsburg Oxbow. The residential areas did not experience any hazards. On the other hand, four large cultivated fields were fully or partially submerged in 2011. These fields may be expected to be entirely submerged in future high floods since they are located within the high flood zone. 


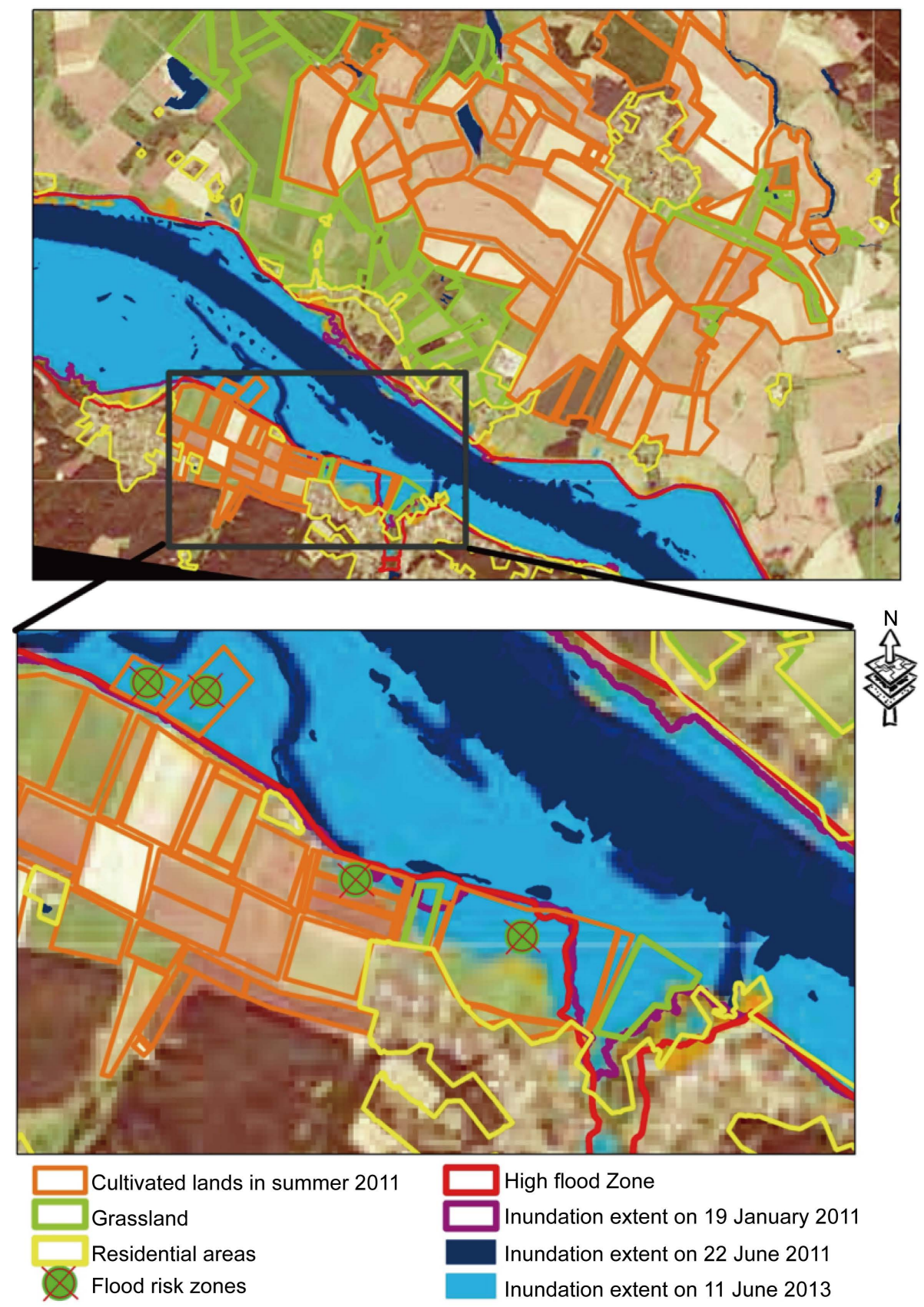

Figure 15. The flood extent of the flood in 2013 created by DLR overlaid with the flood extent in June and January 2011, the residential areas and agricultural land use in Summer 2011 at Walmsburg Oxbow.

In spite of the fact that these fields were flooded in January 2011, they were cultivated with maize and potatoes in summer 2011. During the flood of summer 2013, these cultivated areas were again inundated and caused economic losses to the owners of the land. To achieve sustainable land use in this area, these fields must be included in the flood hazard maps and regulations established to prevent cultivation in these areas, permitting the fields to be used only as grassland, in order to avoid economic losses.

In Figure 16, the cultivated area around Wehningen Oxbow, in contrast to the Walmsburg Oxbow, was not submerged and did not endure any hazards. On the other hand, part of the residential area in the Strachauer Rad, in the city of Dannenberg, Lower Saxony, is located within the high flood zone. However, this area was not 


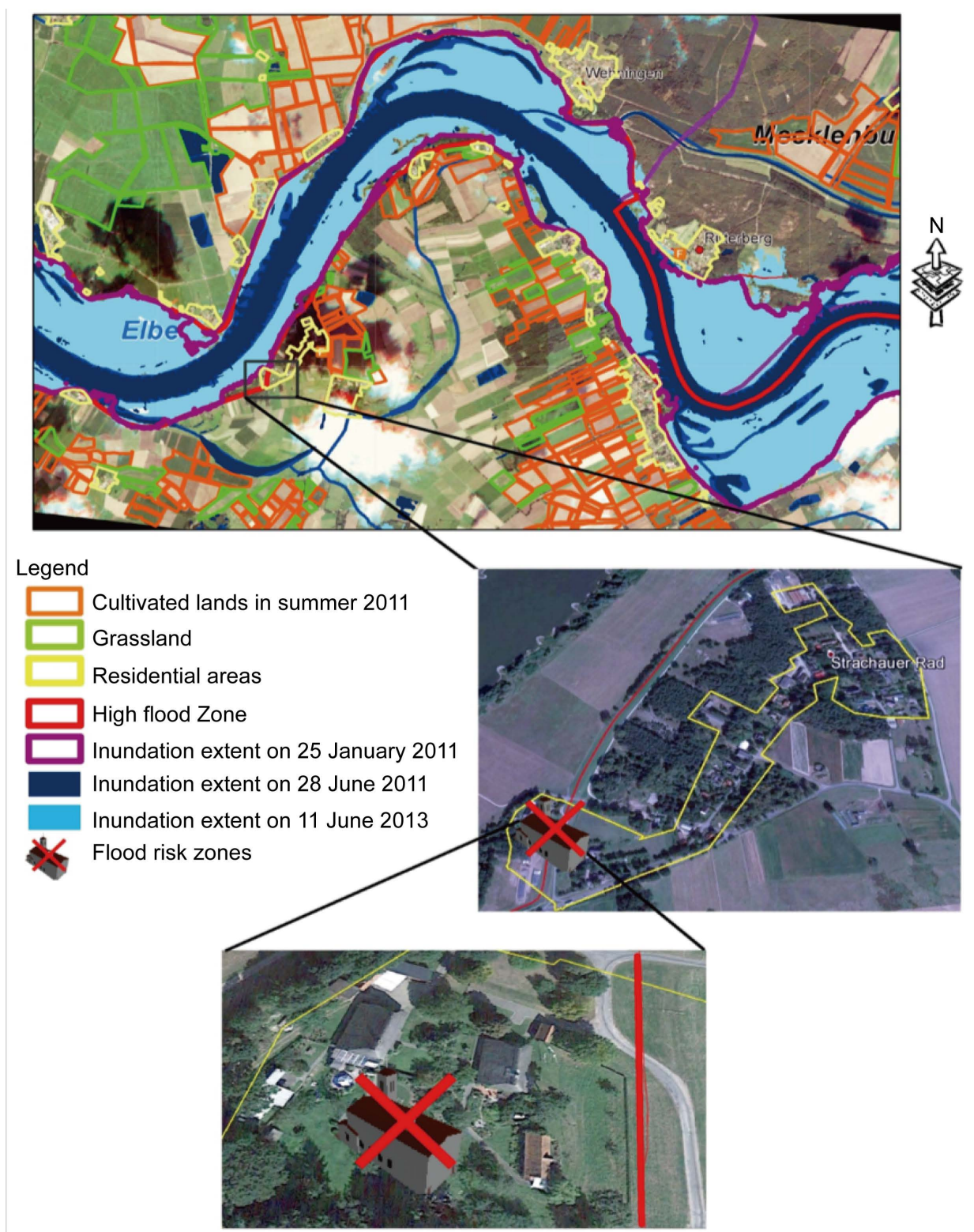

Figure 16. The flood extent due to the floods in 2013 produced by DLR overlaid with the flood extent in June 2011 and January 2011, the residential areas and the agricultural land use in summer 2011 at Wehningen Oxbow.

submerged during the most recent high floods, in 2011 and 2013. Nevertheless, this part of the city should be added to the hazard and risk maps to avoid the possible human and economic losses that may occur due to higher floods. This flood mapping will support sustainable land use in this area.

\section{Concluding Remarks}

In order to achieve sustainable land use on the Middle Elbe River floodplain, up-to-date land use maps during the pre-flood period are essential to determine the hazards that may arise during the post-flood period. In particular, the locations of residential areas must be verified against the maps to ensure that they are safely removed from the high flood zone. Therefore, the residential areas that lie within the extent of flood zone must be included on the risk maps to support the regulatory prevention of (further) building within these risk zones. Moreover, the arable land which has suffered partially or fully from flood events must also be added to the ha- 
zard maps to decrease potential economic losses and to achieve sustainable land use.

The merging of similar pixels into objects diminishes the problem of speckle noise in the TSX imagery and, thus, enables high producer accuracies from the raw images without filtering. The raw images lead to similar or even better results than the Lee-filtered images. Therefore, it is recommended to use the object-based classifier with the raw images to save time and effort. Especially during flood events, flood extent maps are immediately required to identify hazard areas to help reduce human and economic losses. Further, the use of dual-polarized images enhances the classification results and leads to higher producer accuracies than the mono-polarized images. Therefore, it is recommended to use dual-polarization images to attain more accurate LULC maps.

The resulting Decision-Tree procedure, using the rule-based classifier in ENVI EX, resulted in considerably better total producer accuracies, such that about $95 \%$ of the water area was accurately defined, as well as about $90 \%$ of vegetated lands being correctly determined, and around $80 \%$ of the forest and the residential area classes recognized. The $20 \%$ misclassified areas within the forest and residential areas were due to the existence of vegetated areas and trees within the residential areas around the buildings.

The use of texture and spatial attributes with the spectral attributes enhanced the classification results. Applying rules based on the band-average, as a spectral attribute, and the texture-mean facilitated correct identification of about $95 \%$ of the flood extent for post-flood imagery. Furthermore, the use of the texture-entropy attribute enabled recognition of about $90 \%$ of the vegetated lands. The texture-mean attribute enabled efficient distinguishing of residential areas and forest classes.

To conclude, the results show that similar rule sets can be used for the Decision-Tree procedure on two remote study areas in the Elbe River flood plains to achieve higher classification producer accuracies. Thus, the suggested Decision-Tree should be applicable to other remote areas. Therefore, it is recommended to continuously monitor the entire Biosphere Reserve using TSX imagery to deal with construction and/or cultivation within the flood zone. Construction and cultivation in flood plains should be carefully planned according to the flood risk maps to ensure sustainable land use within the Elbe Biosphere.

\section{Acknowledgements}

We are greatly indebted to the administration of the Biosphere Reserve "Niedersächsische Elbtalaue" (Lower Saxonian Elbe Valley Biosphere Reserve) and to the German Aerospace Centre (Deutsches Zentrum für Luftund Raumfahrt, DLR) for providing the satellite images used in this study. We acknowledge the important support of this research provided by a PhD graduate scholarship awarded by LEUPHANA University Lüneburg to Dalia Farghaly.

\section{References}

[1] Brämick, U., Fladung, F. and Doering-Arjes, P. (2008) Aalmanagementplan-Flussgebietsgemeinschaft Elbe, Institut für Binnenfischerei e.V. Potsdam-Sacrow, Potsdam.

[2] Hauf, Y. (2005) The River Basin District Elbe and the Coordinating Areas, MONERIS (Modelling Nutrient Emissions in River Systems). River Basin Community Elbe, Potsdam Institute for Climate Impact Research, Potsdam.

[3] IKSE (2005) Informationsblatt der IKSE Nr. 1 Gastbeiträge und Weitere Informationen Wasserrahmenrichtlinie im Einzugsgebiet der Elbe. Internationale Kommission zum Schutz der Elbe (IKSE), Magdeburg.

[4] Kunkel, R. and Wendland, F. (1998) Der Landschaftswasserhaushalt im Flußeinzugsgebiet der Elbe Verfahren, Datengrundlagen und Bilanzgrößen. Schriften des Forschungszentrums Jülich Reihe Umwelt, 12, Forschungszentrum, Zentralbibliothek, Jülich.

[5] NLWKN (2014) Gauges Location along Elbe River, Niedersächsischer Landesbetrieb für Wasserwirtschaft, Küstenund Naturschutz (NLWKN), Hochwassermeldedienste.

[6] Jutta, G. and Inga, M. (2011) Die Elbe Von der Quelle bis zur Mündung. The Elbe, Komet Verlag, Köln.

[7] UNESCO (2011) UNESCO_Biosphere Reserves in Germany.

[8] Prüter, J., Keienburg, T. and Schreck, C. (2014) Klimafogenanpassung im Biosphärenreservat Niedersächsiche Elbtalaue-Modellregion für nachhaltige Entwicklung Berichte aus den Klimzug-Nord Modellgebieten—Band 5, neue Ausg, TuTech Innovation, Hamburg.

[9] Härdtle, W., Redecker, B., Assmann, T. and Meyer, H. (2006) Vegetation Responses to Environmental Conditions in Floodplain Grasslands: Prerequisites for Preserving Plant Species Diversity. Basic and Applied Ecology, 7, $280-288$. http://dx.doi.org/10.1016/j.baae.2005.09.003 
[10] Urban, B. (2003) River Elbe Ecology_Contributions to a Large Scale Environmental Project. In: Ramesh, R. and Ramachandran, S., Eds., Coastal Urban Environments, Capital Publishing Company, New Delhi, Kolkate, Bangalore, 67-88.

[11] Ludewig, K., Korell, L., Loeffler, F., Scholz, M., Mosner, E. and Jensen, K. (2014) Vegetation Patterns of Floodplain Meadows along the Climatic Gradient at the Middle Elbe River. Flora, 209, 446-455. http://dx.doi.org/10.1016/j.flora.2014.04.006

[12] Kienzler, S., Pech, I., Kreibich, H., Müller, M. and Thieken, A.H. (2014) After the Extreme Flood in 2002: Changes in Preparedness, Response and Recovery of Flood-Affected Residents in Germany between 2005 and 2011. Natural Hazards and Earth System Sciences, 2, 6397-6451. http://dx.doi.org/10.5194/nhessd-2-6397-2014

[13] Mudersbuch, M., Bender, J., Kelln, V. and Jensen, J. (Eds.) (2013) Analysis Flood Frequencies at the Elbe River-Do Recent Extreme Events Affect Design Levels? Proceedings of the International Conference on Water Resources and Environment Research (ICWRER), Koblenz, 3-7 June 2013, 346-362.

[14] Gremli, R., Keller, B., Sepp, T. and Szönyi, M. (2014) European Floods: Using Lessons Learned to Reduce Risks. Zurich Insurance Group Ltd, Zurich.

[15] Bessel, T., Möhrle, S., Dittrich, A., Schröter, K., Mühr, B., Elmer, F., Kunz-Plapp, F., Trieselmann, W. and Kunz, M. (2013) June 2013 Flood in Central Europe-Focus Germany Report 2-Update 1: Impact and Management. Center for Disaster Management and Risk Reduction Technology_CEDIM Forensic Disaster Analysis Group (FDA), Karlsruhe.

[16] Schröter, K., Kunz, M., Elmer, F., Mühr, B. and Merz, B. (2014) What Made the June 2013 Flood in Germany an Exceptional Event? A Hydro-Meteorological Evaluation. Hydrology and Earth System Sciences, 11, 8125-8166. http://dx.doi.org/10.5194/hessd-11-8125-2014

[17] Geller, W. (2004) Schadstoffbelastung nach dem Elbe-Hochwasser 2002 Endbericht des Ad-hoc-Projekts "Schadstoffuntersuchungen nach dem Hochwasser vom August 2002-Ermittlung der Gefährdungspotentiale an Elbe und Mulde” BMBF-Förderkennzeichen PTJ 0330492, UFZ; Kompetenzzentrum Digitaldr, Leipzig, Nürnberg.

[18] Kundzewicz, Z.W., Pińskwar, I. and Brakenridge, G.R. (2013) Large Floods in Europe, 1985-2009. Hydrological Sciences Journal, 58, 1-7. http://dx.doi.org/10.1080/02626667.2012.745082

[19] Begg, C., Luther, J., Kuhlicke, C. and Steinführer, A. (2011) Participation in Central European Flood Risk Management: Social Capacity Building in Practice. Centre for Environmental Research-UFZ, Leipzig.

[20] Balthasar, B. and Edwards, T. (2011) 2011 Rhein (Rhine) and Elbe Basin Floods, Germany—Report of 18th January 2011, Willis Re Analytics Event Response, London.

[21] LHW (2014) Bericht über das Hochwasser im Juni 2013 in Sachsen-Anhalt Entstehung, Ablauf, Management und statistische Einordnung, Landesbetrieb für Hockwasserschutz und Wasserwirtscaft (LHW) Sachsen-Anhalt, AG Oberflächenwasser der FGG Elbe, Magdeburg.

[22] Dallmann, G. (2013) Hydrologische Zusammenfassung zum Hochwasser an Elbe und Weser im Juni 2013. Niedersächsisches Ministerium für Umwelt, Energie und Klimaschutz, Hannover.

[23] Kerner, M. (2014) Risk Nexus. Central European Floods 2013: A Retrospective Flood Resilience Review 05.14. Zurich Insurance Company Ltd, Zurich.

[24] Ouma, Y. and Tateishi, R. (2014) Urban Flood Vulnerability and Risk Mapping Using Integrated Multi-Parametric AHP and GIS: Methodological Overview and Case Study Assessment. Water, 6, 1515-1545. http://dx.doi.org/10.3390/w6061515

[25] Pradhan, B. (2009) Flood Susceptible Mapping and Risk Area Delineation Using Logistic Regression, GIS and Remote Sensing. Journal of Spatial Hydrology, 9, 1-18.

[26] APFM (2013) Flood Mapping. Integrated Flood Management Tools Series No. 20. Associated Programme on Flood Management (APFM), World Meteorological Organization (WMO) and the Global Water Partnership (GWP). Jason DeCaires Taylor, ProLitteris, Zurich.

[27] UNECE (2009) Transboundary Flood Risk Management: Experiences from the UNECE Region. Convention on the Protection and Use of Transboundary Watercourses and International Lakes, United Nations Economic Commission for Europe (UNECE). UNO, New York, Geneva.

[28] Moel, H., Alphen, J. and Aerts, J.C.J.H. (2009) Flood Maps in Europe-Methods, Availability and Use. Natural Hazards and Earth System Sciences, 9, 289-301. http://dx.doi.org/10.5194/nhess-9-289-2009

[29] FLOODsite (2008) Integrated Flood Risk Analysis and Management Methodologies Pilot Study "Elbe River Basin” Executive Summary. Report No.: T21-08-02, Leibniz Institute of Ecological and Regional Development (IOER), Dresden.

[30] EXCIMAPAP (2007) Handbook on Good Practices for Flood Mapping in Europe, European Exchange Circle on Flood Mapping (EXCIMAPAP). 
[31] FEMA (2009) Guide to Flood Maps Using the Flood Map to Improve Your Understanding of Risk. The Federal Emergency Management Agency (FEMA), Arlington.

[32] Chenghu, Z., Luo, J., Zang, C., Li, B. and Wang, S. (2000) Flood Monitoring Using Multi-Temporal AVHRR and RADARSAT Imagery. Photogrametric Engineering \& Remote Sensing, 66, 633-638.

[33] Leenaers, H. and Okx, J.P. (2007) The Use of Digital Elevation Models for Flood Hazard Mapping. Earth Surface Processes and Landforms, 14, 631-640. http://dx.doi.org/10.1002/esp.3290140617

[34] Schnebele, E. and Cervone, G. (2013) Improving Remote Sensing Flood Assessment Using Volunteered Geographical Data. Natural Hazards and Earth System Sciences, 13, 669-677. http://dx.doi.org/10.5194/nhess-13-669-2013

[35] Senthilnath, J., Shenoy, H.V., Rajendra, R., Omkar1, S.N., Mani, V. and Diwakar, P.G. (2013) Integration of Speckle De-Noising and Image Segmentation Using Synthetic Aperture Radar Image for Flood Extent Extraction. Journal of Earth System Science, 122, 559-572. http://dx.doi.org/10.1007/s12040-013-0305-z

[36] Skakun, S., Kussul, N., Shelestov, A. and Kussul, O. (2014) Flood Hazard and Flood Risk Assessment Using a Time Series of Satellite Images: A Case Study in Namibia. Risk Analysis, 34, 1521-1537. http://dx.doi.org/10.1111/risa.12156

[37] Zwenzner, H. and Voigt, S. (2009) Improved Estimation of Flood Parameters by Combining Space Based SAR Data with Very High Resolution Digital Elevation Data. Hydrology and Earth System Sciences, 13, 567-576. http://dx.doi.org/10.5194/hess-13-567-2009

[38] Bhatt, C.M., Rao, G.S., Begum, A., Manjusree, P., Sharma, S.V.S.P., Prasanna, L. and Bhanumurthy, V. (2013) Satellite Images for Extraction of Flood Disaster Footprints and Assessing the Disaster Impact: Brahmaputra Floods of June-July 2012, Assam, India. Current Science, 104, 1692-1700.

[39] Smith, L.C. (1997) Satellite Remote Sensing of River Inundation Area, Stage, and Discharge: A Review. Hydrological Processes, 11, 1427-1439. http://dx.doi.org/10.1002/(SICI)1099-1085(199708)11:10<1427::AID-HYP473>3.0.CO;2-S

[40] Townsend, P.A. (2001) Mapping Seasonal Flooding in Forested Wetlands Using Multi-Temporal Radarsat SAR. Photogrametric Engineering \& Remote Sensing, 67, 857-864.

[41] Giustarini, L., Hostache, R., Matgen, P., Schumann, G.-P., Bates, P.D. and Mason, D.C. (2013) A Change Detection Approach to Flood Mapping in Urban Areas Using TerraSAR-X. IEEE Transactions on Geoscience and Remote Sensing, 51, 2417-2430. http://dx.doi.org/10.1109/TGRS.2012.2210901

[42] Ho, L.T.K., Umitsu, M. and Yamaguchi, Y. (2010) Flood Hazard Mapping by Satellite Images and SRTM DEM in the Vu Gia-Thu Bon Alluvial Plain, Central Vietnam. International Archives of the Photogrammetry, Remote Sensing and Spatial Information Science, 38, 275-280.

[43] Lillesand, T.M., Kiefer, R.W. and Chipman, J.W. (2008) Remote Sensing and Image Interpretation. 6th Edition, John Wiley \& Sons, Hoboken.

[44] Manjusree, P., Prasanna K.L., Bhatt, C.M., Rao, G.S. and Bhanumurthy, V. (2012) Optimization of Threshold Ranges for Rapid Flood Inundation Mapping by Evaluating Backscatter Profiles of High Incidence Angle SAR Images. International Journal of Disaster Risk Science, 3, 113-122. http://dx.doi.org/10.1007/s13753-012-0011-5

[45] Richards, J.A. (2009) Remote Sensing with Imaging Radar. Signals and Communication Technology. Springer-Verlag, Berlin. http://dx.doi.org/10.1007/978-3-642-02020-9

[46] Sandro, M. (2010) Automatic Near Real-Time Flood Detection in High Resolution X-Band Synthetic Aperture Radar Satellite Data Using Context-Based Classification on Irregular Graphs. Dissertation, Fakultät für Geowissenschaften, LMU München, München.

[47] Ulaby, F.T., Moore, R.K. and Fung, A.K. (1982) Microwave Remote Sensing: Active and Passive. Theory. Vol. IIRadar Remote Sensing and Surface Scattering and Emission. Addison-Wesley Publishing Company, Boston.

[48] Zalite, K., Voormansik, K., Olesk, A., Noorma, M. and Reinart, A. (2014) Effects of Inundated Vegetation on X-Band HH-VV Backscatter and Phase Difference. IEEE Journal of Selected Topics in Applied Earth Observations and Remote Sensing, 7, 1402-1406. http://dx.doi.org/10.1109/JSTARS.2013.2279552

[49] Ramsey, E., Rangoonwala, A. and Bannister, T. (2013) Coastal Flood Inundation Monitoring with Satellite C-Band and L-Band Synthetic Aperture Radar Data. Journal of the American Water Resources Association, 49, 1239-1260. http://dx.doi.org/10.1111/jawr.12082

[50] Elba, E., Farghaly, D. and Urban, B. (2014) Modeling High Aswan Dam Reservoir Morphology Using Remote Sensing to Reduce Evaporation. International Journal of Geosciences, 5, 156-169. http://dx.doi.org/10.4236/ijg.2014.52017

[51] Farghaly, D., Urban, B., Lohmann, P. and Elba, E. (Eds.) (2011) Differentiation and Extend of Aquatic Weeds over Lake Kyoga, Uganda by Multiple Remote Sensing Technology. DLR.

[52] Pulvirenti, L., Pierdicca, N., Chini, M. and Guerriero, L. (2011) An Algorithm for Operational Flood Mapping from Synthetic Aperture Radar (SAR) Data Using Fuzzy Logic. Natural Hazards and Earth System Sciences, 11, 529-540. 
http://dx.doi.org/10.5194/nhess-11-529-2011

[53] DLR (2007) TerraSAR-X Das Deutsche Radar-Auge im All. The German Radar Eye in Space. Deutschen Zentrum für Luft und Raumfahrt (DLR), Göttingen.

[54] ENVI (2008) ENVI Feature Extraction Module User’s Guide: Feature Extraction Module Version 4.6. http://www.exelisvis.com/portals/0/pdfs/envi/feature_extraction_module.pdf

[55] Farghaly, D., Elba, E. and Urban, B. (2014) Observing the Middle Elbe Biosphere in Germany by Means of TerraSAR-X Images. International Journal of Geosciences, 5, 196-205. http://dx.doi.org/10.4236/ijg.2014.52021

[56] Burt, J.E., Barber, G.M. and Rigby, D.L. (2009) Elementary Statistics for Geographers. 3rd Edition, Guilford Press, New York, London.

[57] Lang, M., Townsend, P. and Kasischke, E. (2008) Influence of Incidence Angle on Detecting Flooded Forests Using C-HH Synthetic Aperture Radar Data. Remote Sensing of Environment, 112, 3898-3907. http://dx.doi.org/10.1016/j.rse.2008.06.013

[58] DLR (2013) Germany Floods 2013-Monitoring. Center for Satellite Based Crisis Information (ZKI) - DLR, Elbe Dannenberg, Internet. 